NBER WORKING PAPER SERIES

\title{
THE IMPACT OF UNEMPLOYMENT BENEFIT EXTENSIONS ON EMPLOYMENT: THE 2014 EMPLOYMENT MIRACLE?
}

\author{
Marcus Hagedorn \\ Iourii Manovskii \\ Kurt Mitman \\ Working Paper 20884 \\ http://www.nber.org/papers/w20884 \\ NATIONAL BUREAU OF ECONOMIC RESEARCH \\ 1050 Massachusetts Avenue \\ Cambridge, MA 02138 \\ January 2015
}

We thank seminar participants at the Bundesbank, Census Bureau, CFS at Goethe University, CUNY Graduate Center, ECB, Edinburgh, EIEF, Greater Stockholm Macro Group, IIES, Maryland, Toulouse, University of Oslo, UCL, UConn, Wisconsin, 2015 NBER Summer Institute Macro Perspectives Group, 2015 Society of Economic Dynamics, the 2015 International Conference on Labor Markets in/after Crises and the 11th Joint ECB/CEPR Labour MarketWorkshop Job creation after the crisis" for helpful comments. Support from the National Science Foundation Grant Nos. SES-0922406 and SES-1357903 is gratefully acknowledged. The views expressed herein are those of the authors and do not necessarily reflect the views of the National Bureau of Economic Research.

NBER working papers are circulated for discussion and comment purposes. They have not been peer-reviewed or been subject to the review by the NBER Board of Directors that accompanies official NBER publications.

(C) 2015 by Marcus Hagedorn, Iourii Manovskii, and Kurt Mitman. All rights reserved. Short sections of text, not to exceed two paragraphs, may be quoted without explicit permission provided that full credit, including $(\odot$ notice, is given to the source. 
The Impact of Unemployment Benefit Extensions on Employment: The 2014 Employment Miracle?

Marcus Hagedorn, Iourii Manovskii, and Kurt Mitman

NBER Working Paper No. 20884

January 2015, Revised May 2016

JEL No. E24,J63,J64,J65

\section{ABSTRACT}

We measure the aggregate effect of unemployment benefit duration on employment and the labor force. We exploit the variation induced by Congress' failure in December 2013 to reauthorize the unprecedented benefit extensions introduced during the Great Recession. Federal benefit extensions that ranged from 0 to 47 weeks across U.S. states were abruptly cut to zero. To achieve identification we use the fact that this policy change was exogenous to cross-sectional differences across U.S. states and we exploit a policy discontinuity at state borders. Our baseline estimates reveal that a $1 \%$ drop in benefit duration leads to a statistically significant increase of employment by 0.019 log points. In levels, 2.1 million individuals secured employment in 2014 due to the benefit cut. More than 1.1 million of these workers would not have participated in the labor market had benefit extensions been reauthorized.

Marcus Hagedorn

Department of Economics, University of Oslo, Box 1095 Blindern, 0317 Oslo, Norway marcus.hagedorn@econ.uio.no

Iourii Manovskii

Department of Economics

University of Pennsylvania

160 McNeil Building

3718 Locust Walk

Philadelphia, PA 19104

and NBER

manovski@econ.upenn.edu
Kurt Mitman

Institute for International Economic Studies

Stockholm University

10691 Stockholm

SWEDEN

kurt.mitman@iies.su.se 


\section{Introduction}

Our objective in this paper is to assess the impacts of unemployment benefit extensions on the labor force and employment. Measuring the magnitude of these effects is manifestly important for understanding the economic consequences of this widely used policy instrument. Yet, the existing literature provides little information on the size, let alone the sign of these effects. In the theoretical literature the effect of benefit extensions on employment is generally ambiguous. Basic decision theory suggests that some unemployed may increase their search effort in response to a cut in benefits, while others, who were mainly searching to qualify for benefits, might drop out of the labor force once losing eligibility, leading to offsetting effects on employment. Equilibrium job search theory typically implies a positive effect of a cut in benefit duration on job creation. This makes it easier for the unemployed to find jobs and might induce those previously out-of-labor force to rejoin the labor force, leading to an increase in

employment with an ambiguous effect on unemployment since the number of job vacancies and the number of searchers increases at the same time. The empirical micro literature has focused almost exclusively on measuring the effects of benefit eligibility on the search effort of unemployed workers - a focus that is too narrow to infer the total impact of benefit duration on employment. The estimates in the quantitative macro literature vary widely depending on the value of parameters which are notoriously difficult to identify. Moreover, the literature generally ignores the effect of policies on participation decisions of those out-of-the-labor force, which limits their ability to measure the total effect on employment. Indeed, in the data the flow from non-participation into employment accounts for over $60 \%$ of all transitions into employment.

We propose to sidestep these difficulties by directly measuring the employment and labor force impacts of a large nationwide cut in benefit duration in December 2013. The attractive feature of this quasi-natural experiment is that its effects can be measured using standard empirical techniques that do not require imposing assumptions of a particular labor market model on the data. Specifically, we measure the impact of the December 2013 decision by Congress to terminate the Emergency Unemployment Compensation Act of 2008 (EUC08) which abruptly lowered benefit duration in all states to their regular duration of typically 26 weeks. This decision terminated an unprecedented extension of unemployment benefit 
durations adopted by policymakers following the onset of the Great Recession. While benefit durations began declining in some of the states starting in 2011, even by the end of 2013, right before the reform and long after the recession had ended, the average benefit duration across U.S. states stood at 53 weeks.

The decision to eliminate benefit extensions at the end of 2013 was quite controversial. Summarizing the conventional wisdom at the time, the Council of Economic Advisers and the Department of Labor (2013) predicted that 240,000 jobs would be lost in 2014 because of the negative impact on aggregate demand. Many economists voiced a concern, first articulated in Solon (1979), that without access to benefits unemployed workers will stop searching for jobs and will exit the labor force instead.

However, the U.S. labor market performance in 2014 surprised many observers (though not all, see e.g. Mulligan (2015)). Figure A-1 in the Appendix reports some basic aggregate statistics. Average employment growth was about 25\% higher in 2014 than in the best of several preceding years. The employment-to-population ratio rose. The unemployment rate declined sharply. In contrast to typical predictions, the labor force participation rate suddenly halted its steady secular decline. The number of job vacancies that employers were trying to fill increased sharply.

At the national level, however, it is difficult to ascertain the extent to which these aggregate labor market developments were induced by the elimination of unemployment benefit extensions. The fact that aggregate productivity growth was slower in 2014 than in the preceding years eliminates the most prominent alternative explanation. While that can help explain the low observed wage growth in 2014, it cannot reconcile the low wage growth with the otherwise booming labor market. However, based on aggregate data alone, it appears difficult to rule out the possibility that some other aggregate shocks (coincidental with the decline in benefit duration) suddenly spurred the decisions of firms to create job vacancies and of jobless workers to accept them.

To overcome this difficulty, we take a different route in this paper. In particular, we exploit the fact that, at the end of 2013, federal unemployment benefit extensions available to workers ranged from 0 to 47 weeks across U.S. states. As the decision to abruptly eliminate all federal extensions applied to all states, it was exogenous to economic conditions of individual states. In particular, states did not choose to cut benefits based on, e.g. their employment in 2013 
or expected employment growth in 2014. This allows us to exploit the vast heterogeneity of the decline in benefit duration across states to identify the labor market implication of unemployment benefit extensions. Note, however, that the benefit durations prior to the cut, and, consequently, the magnitudes of the cut, likely depended on economic conditions in individual states. Thus, the key challenge to measuring the effect of the cut in benefit durations on employment and the labor force is the inference on labor market trends that various locations would have experienced without a cut in benefits. Much of the analysis in the paper is devoted to the modeling and measurement of these trends. However, to immediately reduce the importance of heterogenity of underlying employment trends, we focus the analysis on comparisons of labor force and employment dynamics between counties that border each other but belong to different states and thus experience different changes in benefit durations. This is helpful because, as we explain below, underlying economic fundamentals are expected to evolve more similarly across counties bordering each other than across states or randomly paired counties.

After describing the institutional features of the U.S. unemployment insurance system and the details of the policy change in December 2013, in Section 2 we provide a very basic description of patterns in the data. We find that employment growth was much higher in 2014 in the border counties that experienced a larger decline in benefit durations relative to the adjacent counties. What makes this finding even more striking is that year after year prior to 2014 the relative employment growth was lower in the high benefit counties. The abrupt reversal in the relative employment growth trend of border counties belonging to high benefit states in December 2013, right at the time when the benefit durations were cut, strongly suggests that our analysis indeed identifies the implications of this particular policy change. There were no other policy changes at the turn of 2014 that could have differentially affected states depending on their pre-reform benefit duration and had significant labor market implications.

The primary focus of the formal analysis in the paper is on measuring the counterfactual trends in labor force and employment that border counties would have experienced without a cut in benefits. We build on two distinct methodologies in the literature for doing so. The methodologies differ primarily in whether the post-reform observations are used for measuring the counterfactual employment trends. The more common approach in the macro and labor 
literature is to use both pre- and post-reform information. We develop the associated econometric methodology for formally measuring the effects of unemployment benefit extensions in Section 3. Specifically, we consider three models of county-specific trends that differ in their flexibility and the ease of interpretation. The first one is the workhorse in the literature due to its parsimony and its reliance on easily interpretable variables. It allows for permanent (over the estimation window) differences in employment across border counties which could be induced by the differences in other policies (e.g., taxes or regulations) between the states these counties belong to. Moreover, employment in each county is allowed to follow a distinct deterministic time trend. The model also includes aggregate time effects and controls for the effects of unemployment benefit durations in the pre-reform period.

The second and third models are motivated by the economics underlying the existence of potentially heterogeneous trends across border counties. Specifically, these trends reflect the systematic response of underlying economic conditions across counties with different benefit durations to various aggregate shocks and the heterogeneity is induced by differential exposure of counties to these aggregate disturbances. For example, Holmes (1998) argued that border counties may differ in the share of manufacturing industry employment, due to different state right-to-work laws. In this case, aggregate shocks affecting the relative productivity of manufacturing industry will have a different impact on the employment in the two border counties. Similarly, foreclosure laws differ across states, implying that aggregate shocks to house prices have a different impact on the construction industry, and, say, demand for goods and services in the two border counties. This may also induce different trends in employment in the two border counties. Thus, there are numerous aggregate shocks that potentially induce different trends across border county pairs.

Motivated by this theory of trend heterogeneity, in the second model we extend the original specification to also include various measurable aggregate factors (e.g., oil prices, construction employment, etc.) and estimate county-specific loadings on these factors to capture the heterogeneous exposure of counties to these observed aggregate variables. While this specification remains very transparent, the ability of the model to identify the correct counterfactual trends depends on the selection of the appropriate aggregate factors. We bypass the need to select individual aggregate factors in the third model, although at the cost of losing interpretability of the aggregate factors. Specifically, we use a very flexible interactive effects 
specification of the county-specific trends developed in Bai (2009). The interactive effects estimator simultaneously identifies the important unobserved aggregate factors and measures their heterogeneous impacts through county-specific factor loadings. Note that because factors and loadings are simultaneously estimated, measuring of the counterfactual trends following the reform necessitates the use of the post-reform data.

The second methodological approach that we develop in Section 6 builds on the event study methodology. In this approach the employment and labor force trends across counties are estimated based on the pre-event (cut in benefit duration) information only. The estimates are used to predict the evolution of the relevant labor market variables in the absence of the unexpected cut in benefits. A comparison of the predicted values of these variables to the actually observed ones following the benefit cut reveals the effect of the change in policy. Using only the pre-event window for estimation minimizes the effect of the event itself on the estimated trends.

The results of the empirical analysis based on these two methodologies are presented and discussed in Sections 4 and 6, respectively. While there is clear variation across the four approaches we use to estimate the counterfactual employment trends across counties, overall the results are quite consistent. This happens because counterfactual employment trends in the labor force and in employment estimated using the four approaches we consider are fairly similar, and capture quite well the small differences in employment growth of neighboring counties. This allows us to conclude that, conditional on these trends, the common trend assumption is satisfied. We can therefore obtain consistent estimates of the effects of the cut in benefit durations on labor force and employment. All four specifications imply that changes in unemployment benefit duration have a large and statistically significant effect on employment: a 1 percent drop in benefit duration increases employment by 0.0144 to 0.0233 log points across specifications. Importantly, we also find that more than half of the increase in employment attributed to the cut in benefits was due to an increase in the labor force. Our analysis thus implies that, not only did the unemployed not drop out of the labor force because of losing entitlement to benefits, but instead those previously not participating in the labor market decided to enter the labor force. These effects are not unexpected in light of equilibrium labor market theory which implies an increase in job creation in response to a cut in benefit duration. The increased availability of jobs than draws non-participants into the 


\section{labor market. ${ }^{1}$}

These estimates are based on the differential response of the labor force and employment between bordering counties to changes in benefit duration. To the extent that economic activity reallocates in response to differences in benefit durations across counties, the effects of such a reallocation are reflected by our estimates. It would be desirable, however, to be able to aggregate these estimates to obtain the effect of the nation-wide change in benefit duration that precludes the possibility of reallocation of economic activity. To this end, we document that individuals do not change the location of employment in response to changes in benefits. In addition, we do not find any differential impact of benefit duration changes on employment shares of tradeable and non-tradeable sectors. Using a simple trade model with frictional labor markets, we show that these observations allow us to aggregate county-level elasticities to the nation-wide one. Empirically, we find that our estimates imply that the cut in benefit duration accounted for between 50 and 80 percent of aggregate employment growth in 2014 .

As follows from the discussion above, to help guide economic theory, the joint evolution of employment and labor force in response to unemployment benefit duration changes is most informative. The only data source in the U.S. that contains both measures at the countylevel at a reasonably high frequency is the Local Area Unemployment Statistics (LAUS). Conveniently for our purposes, both variables are also consistently defined and represent the counts of individuals in different employment states at each point in time. A complementary data set that is often used to measure county-level job counts covered by the unemployment insurance system is the Quarterly Census of Employment and Wages (QCEW). In Section 5, we repeat the entire analysis using QCEW data. We find that across all four specifications that we consider, changes in unemployment benefits have a large and statistically significant effect on job counts: a 1 percent drop in benefit duration increases the number of jobs by 0.010 to $0.0236 \log$ points. The point estimates for the increase in the number of jobs is somewhat smaller than the estimate of the effect on employment. This might indicate that a cut in benefits leads to an increase in the number of full-time jobs at the expense of part-time jobs. ${ }^{2}$

\footnotetext{
${ }^{1}$ The theoretical prediction that an increase in job availability draws non-participants into the labor market is the standard one in the literature. See Pissarides (2000) Ch. 7 for a textbook treatment and Krusell et al. (2015) for a modern quantitative evaluation and additional references.

${ }^{2}$ This happens because QCEW counts the number of jobs while LAUS counts the number of individuals who have at least one job. Thus, for example, if a worker holding two part-time jobs secures a single full-time job, the QCEW job count would decline by one while LAUS employment would not be affected.
} 
This is not the only possibility, however, since the covered population also differs across the two data sets.

The only other paper to provide a direct estimate of the total impact of unemployment benefit extensions on employment is Hagedorn et al. (2013). The objective of that paper was to measure the effects of benefits on unemployment in a way that is consistent with the standard equilibrium labor search model and to assess whether the model provides a coherent rationalization of the joint evolution of various labor market variables in response to unemployment benefit extensions. That paper exploits multiple changes in benefits over time and space which necessitates the development of a novel structural measurement methodology that controls for agents' expectations regarding future policy changes that is consistent with the theoretical model. Our focus in this paper is instead on the measurement of the effects of a one-time permanent change in unemployment benefit extensions on employment. We exploit the variation induced by the policy reform that lends itself to the analysis using the standard tools developed by labor economists. This allows us to conduct the measurement without imposing any theoretical restrictions of a particular labor market model. Nevertheless, we compare the results in the two papers below and find that they imply a quantitatively similar negative impact of benefit extensions on employment. In addition, Mulligan (2015) computes the employment effect of the policy reform based on his measure of the change in implicit marginal tax rates on work associated with the reform and obtains a very similar aggregate employment impact to the one we find. Johnston and Mas (2015) study a similar, albeit smaller, policy reform and find a significant positive employment impact of the abrupt cut of benefit duration in Missouri in 2011. While our estimates based on the nation-wide reform have the same sign, they are two to three times smaller in magnitude than theirs.

\section{Data and the Unemployment Insurance Reform}

\subsection{Policy Environment}

Prior to the onset of the Great Recession, unemployed workers in most states qualified for 26 weeks of unemployment compensation paid by the state in which the lost job was located. ${ }^{3}$ In

\footnotetext{
${ }^{3}$ Note that benefit eligibility is based on the location of employment, not the residence of the worker.
} 
response to the deterioration of labor market conditions, the federal Emergency Unemployment Compensation (EUC08) program was enacted in June 2008. The program started by allowing for an extra 13 weeks of benefits to all states and was gradually expanded to have 4 tiers, providing potentially 53 weeks of federally financed additional benefits. The availability of each tier was dependent on state unemployment rates. The EUC08 program was not originally envisioned to last for many years, but was periodically reauthorized by Congress. The last annual reauthorization took place in December 2012.

In addition, the Extended Benefits (EB) program allows for 13 or 20 weeks of extra benefits in states with elevated unemployment rates. The EB program is a joint state and federal program. The federal government pays for half of the cost, and determines a set of "triggers," related to the state insured and total unemployment rates, that the states can adopt to qualify for extended benefits. At the onset of the recession, many states chose to opt out of the program or only adopt high triggers. The American Recovery and Reinvestment Act of 2009 turned this into a federally funded program. Following this, many states joined the program and several states adopted lower triggers to qualify for the program. Most states wrote their legislation implementing their EB program in a way that provided for their participation only as long as federal government paid for 100 percent of the cost. The provision for federal financing of the EB program was reauthorized together with reauthorizations of the EUC08 program.

An important feature of the EB program is that many triggers available to the states under the federal law contain look-back provisions. In particular, the state under those triggers qualified for federal financing only if state unemployment was 110 or 120 percent (depending on a trigger) higher than in the preceding two years. In other words, the EB program could be made available under those triggers only if unemployment is rising. Consequently, starting in 2011 some states began losing eligibility for the EB program. ${ }^{4}$ As total duration of available unemployment benefits began declining so did the unemployment rate resulting in some states also losing eligibility for some of the tiers of the EUC08 program.

As a result, by December 2013 there was substantial heterogeneity in the actual unemployment benefit durations across U.S. states. As Table 1 shows, 3 states had 73 weeks of benefits available, 20 states had 61-63 weeks, 9 states had 54-57 weeks, 18 states had 40-49

\footnotetext{
${ }^{4}$ To mitigate this effect, the federal government temporarily gave states an option of using a three year look-back period.
} 
weeks, and one state had 19 weeks. These data on unemployment benefit durations in each state is based on trigger reports provided by the Department of Labor. These reports contain detailed information for each of the states regarding the eligibility and activation status of the EB program and different tiers of the EUC08 program. ${ }^{5}$

In December 2013, Congress chose not reauthorize the EUC08 program. As there is no "phase-out" period for EUC08 payments, all EUC08 payments ceased abruptly in all states when the program ended. Specifically, individuals who exhausted regular state unemployment compensation after December 21, 2013 (December 22, 2013 in NY) were no longer eligible for EUC08. For unemployed individuals already participating in the EUC08 program, the last payable week of EUC08 benefits was the week ending December 28, 2013 (December 29, 2013 in NY) ${ }^{6}$.

From the moment the unemployment benefit extensions came to an end in December 2013, newly unemployed individuals could only qualify for the regular state unemployment compensation for a duration of 26 weeks in most states. Some states had less than 26 weeks available in 2014, including Arkansas (25), Florida (16), Georgia (18), Kansas (20), Michigan (20), Missouri (20), North Carolina (19) and South Carolina (20). Two states - Massachusetts (30) and Montana (28) - offered more generous benefit durations. Thus, the average benefit duration across states dropped from 53 to 25 weeks in December 2013.

An important property of the decision not to renew benefit extensions in December 2013 is that it applied to all states, regardless of their economic conditions. In particular, the states could not choose whether to be treated by this reform, for example, based on their employment in 2013 or expected employment growth in 2014. The fact that the policy change was exogenous from the point of view of an individual state, allows for a relatively straightforward identification of its labor market impact. This contrasts sharply with the gradual decline in benefit durations in many states since 2011. While those declines could have had significant labor market implications, those policy changes were endogenous to a state's labor market conditions, making the identification of the effects of policies challenging.

While from the outset, the federal unemployment benefit extension program was under-

\footnotetext{
${ }^{5}$ See http://ows.doleta.gov/unemploy/trigger/ for trigger reports on the EB program and http://ows.doleta.gov/unemploy/euc_trigger/ for reports on the EUC08 program.

${ }^{6}$ All states had triggered off the EB program by the end of 2012, so no states were offering extended benefits under this program in December 2013.
} 
Table 1: Benefit Duration across States in December 2013

\begin{tabular}{|c|c|}
\hline Weeks of Benefits & states \\
\hline 73 weeks & Illinois, Nevada, Rhode Island \\
\hline 63 weeks & $\begin{array}{l}\text { Alaska, Arizona, California, Connecticut, Delaware, DC, } \\
\text { Indiana, Kentucky, Louisiana, Maryland, Massachusetts, } \\
\text { Mississippi, New Jersey, New York, Ohio, Oregon, } \\
\text { Pennsylvania, Tennessee, Washington }\end{array}$ \\
\hline 61 weeks & Arkansas \\
\hline 57 weeks & Michigan \\
\hline 54 weeks & $\begin{array}{l}\text { Alabama, Colorado, Idaho, Maine, New Mexico, } \\
\text { Texas, West Virginia, Wisconsin }\end{array}$ \\
\hline 49 weeks & Missouri, South Carolina \\
\hline 44 weeks & Georgia \\
\hline 40 weeks & $\begin{array}{l}\text { Florida, Hawaii, Iowa, Kansas, Minnesota, Montana, Nebraska, } \\
\text { New Hampshire, North Dakota, Oklahoma, South Dakota, } \\
\text { Utah, Vermont, Virginia, Wyoming }\end{array}$ \\
\hline 19 weeks & North Carolina \\
\hline
\end{tabular}


stood to be temporary, the decision to stop the program came largely as a surprise. Indeed, by December 2013 the program had been re-authorized a dozen of times. By that time it had paid benefits for a record 66 months, over two years longer than any prior discretionary benefit extension program. However, the U.S. unemployment rate was higher and the long-term unemployment rate was at least twice as high as it was at the expiration of every previous unemployment benefit extension program. Moreover, the Council of Economic Advisors, the Congressional Budget Office and others argued forcefully for the reauthorization on the grounds that EUC08 is among policies with "the largest effects on output and employment per dollar of budgetary cost." In light of this, few expected Congress to terminate the program in December 2013. Even following Congress' decision, there was likely some uncertainty regarding the finality of the program throughout the first half of 2014. For example, on April 7, 2014, the Senate narrowly approved a bipartisan bill that would have restored (retroactively to December 2013) federal funding for extended unemployment benefits. The bill faced a determined opposition in the House of Representatives, which refused to hold a vote on it. Note that, to the extent that economic agents were able to forecast the expiration of unemployment benefit extensions prior to December 2013 and adjusted their actions accordingly, and to the extent that they were uncertain about the possibility of the extensions being re-authorized at some point in 2014, our estimates will provide a lower bound on the effects of the policy change.

\section{$2.2 \quad$ A First Look at the Data}

As a first step in exploring whether this exogenous policy change helps account for some of the observed rise in employment, we compare the evolution of employment in a sample of county pairs that belong to different states and share a border, implying that many of the counties within pairs had different benefit durations in December 2013. There are 1,175 such border county pairs for which we have complete data (807 of which consisted of counties with different benefit durations in December 2013). County-level data on employment and the labor force are from the Local Area Unemployment Statistics (LAUS) provided by the Bureau of Labor Statistics. $^{7}$

\footnotetext{
${ }^{7} \mathrm{ftp} / / / \mathrm{ftp}$. bls.gov/pub/time.series/la/. Data accessed March 6, 2015. It is theoretically possible that the BLS estimation procedures to some extent impute county-level employment and labor force using their state-
} 


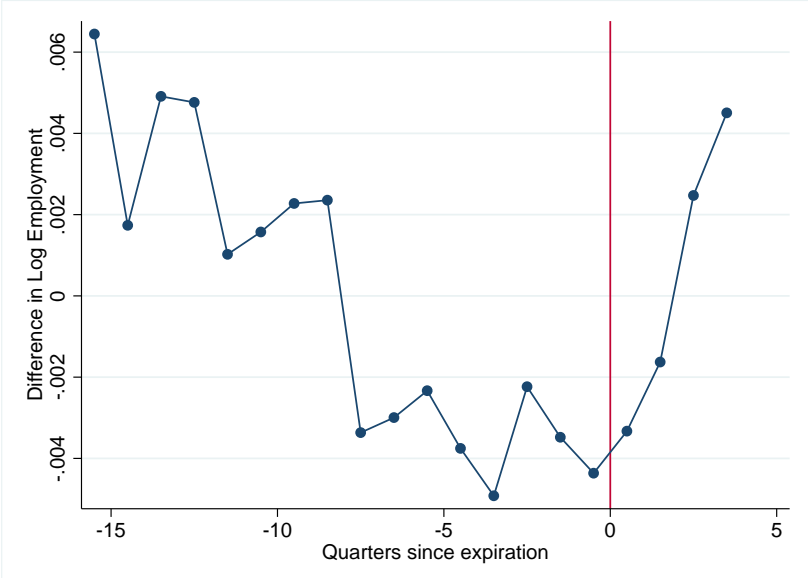

(a) Difference in Log Employment

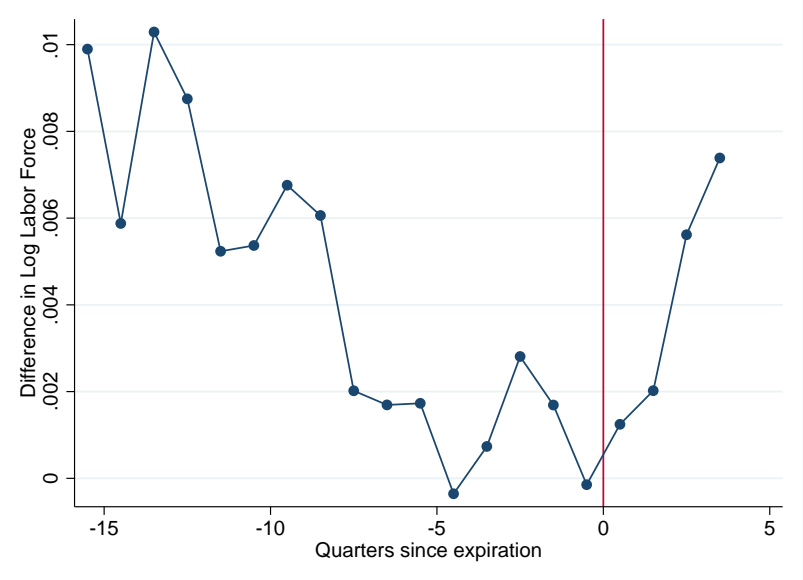

(b) Difference in Log Labor Force

Figure 1: Difference of employment and labor force between high and low benefit border counties (benefit differences measured in December 2013). Vertical line indicates EUC expiration.

Figure 1 shows the average difference in quarterly employment and labor force across all border counties from 2010 to 2014, where the county which had higher benefits in December 2013 is first. For example, Fairfax County, Virginia had 40 weeks of benefits available in December 2013, whereas it's border county in Maryland, Montgomery County, had 63 weeks of benefits available. Thus, in every period the figure would reflect the employment rate in Montgomery County minus the employment rate in Fairfax County. The series represents the average of such differences among all border county pairs.

Figure 1 indicates that after a long period of relative employment and labor force losses, the high benefit counties experienced a sharp relative employment and labor force gain in 2014. To verify that this pattern is unique to 2014 and is not an artifact of our assignment of counties to the two groups based on benefit duration in December 2013, we repeat the experiment in every quarter since 2010 by constructing the difference in employment and in the labor force across border counties based on the duration of benefits in that quarter. To simplify the presentation of the results, we summarize each resulting figure by one point in Figure 2. Specifically, each point represents the difference between high and low benefit border counties in the difference in employment or labor force in the year following that quarter and

level values. This has no material impact on the analysis in this paper since the policy change was exogenous to cross-sectional differences across U.S. states. In addition, our formal analysis includes estimating counterfactual employment trends for each county that are allowed to capture the potential residual impact of state-level trends. 


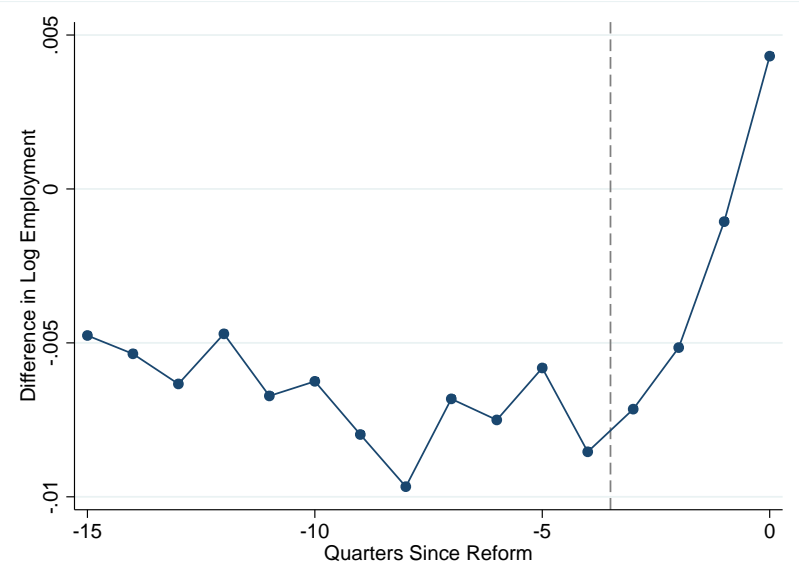

(a) Difference in Log Employment

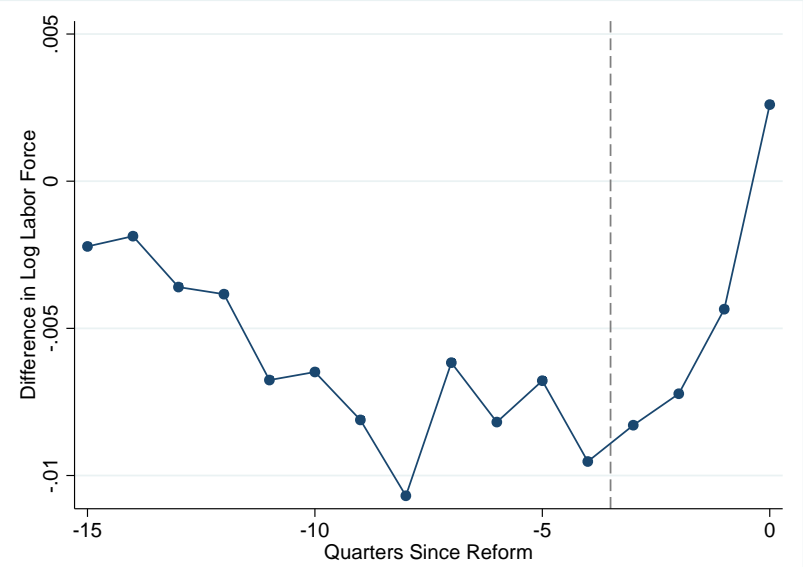

(b) Difference in Log Labor Force

Figure 2: Difference between high and low benefit border counties (benefit differences defined in the corresponding quarter) of the difference in employment and labor force growth in the year after and year before the corresponding quarter. Points to the right of the dashed line include data post EUC expiration.

the year preceding it. Note, that points to the right of the dashed line include data post-EUC expiration. They imply that the fast growth of relative employment and labor force in counties that had high benefit duration in December 2013 is a unique development. For example, the high benefit duration counties in December 2012 did not experience a faster employment growth in 2013 relative to their lower benefit duration counterparts. To put this differently, the actual reform in December 2013 was followed by a fast recovery of relative employment in counties with high benefit durations just before the reform. Performing "placebo" reforms in any other quarter of the sample does not indicate fast growth of employment among counties with high benefit durations on the eve of the placebo reform. ${ }^{8}$

The idea of identification of the effect of benefit duration on employment is simple. The decision to cut benefit duration was exogenous from the point of view of every individual county but the magnitude of the cut depended on the duration of benefits in December 2013. A county with high benefit duration experienced a larger cut than a county with already low benefit duration. We then compare the difference in employment across the two counties

\footnotetext{
${ }^{8}$ It is interesting to note the abrupt changes in 2012/Q1 in the series in Figures 1 and 2. There was a significant cut in benefit durations in that quarter with durations falling more in the counties that by December 2013 had lower duration than their counterparts across the state border. Contemporaneously, counties that experienced larger cuts in benefits in 2012/Q1 tended to have higher benefits than their paired border counties. Thus, both figures suggest higher employment growth in counties that experienced cut in benefits in 2012/Q1, although we are not exploiting that variation for identification in this paper.
} 
before the reform (benefit duration cut in December 2013) to the difference in employment after the reform. In contrast to a standard diff-in-diff analysis where a control group is not treated, all counties are treated here but at a different intensity. The county with high benefits prior to the reform in December 2013 experiences a larger reduction in benefit duration and thus a larger treatment than the neighboring county with low duration which is treated at a lower intensity. We refer to the first county as the treated one and to the latter one as the control one whenever such an analogy to the standard diff-in-diff methodology clarifies our approach. Conducting this comparison of treatment and control counties for all county pairs in the data provides an estimate of the employment effect induced by the benefit reduction.

The typical diff-in-diff logic implies that permanent differences in the level of employment between two neighboring counties are not a concern. Even if these differences are related to the different benefit duration levels in the past, the double differencing eliminates such differences in the level of employment. However, to obtain an unbiased estimate, it is required that the benefit duration in December 2013 was unrelated to a preexisting trend in employment that continued in 2014. To clarify this potential concern with an example, suppose that counties with high benefit duration in December 2013 had a positive employment trend in 2013 that would had continued in 2014 even without the benefit duration cut. In this case, the analysis would yield an upward biased estimate of the effect of benefit duration, since the employment gain in 2014 would be fully attributed to the benefit cut, whereas it is partly the result of a continuing trend. In contrast, if the control county with low benefit duration prior to the reform had the same trend in employment as the treated neighboring county with high benefit duration (common trend assumption), there would be no systematic difference in employment between the counties in the absence of a reform. In this case one can attribute the difference in employment in 2014 to the reform.

Note that our strategy of comparing neighboring counties from different states instead of some arbitrary counties or states (with different benefits) makes the common trend assumption a fairly reasonable one. As the median border county has only one half of one percent of its state's employment, it seems plausible that changes in employment trends in most individual counties are unlikely to induce unemployment policy changes determined at the state level. This is not a necessary condition, however. More importantly, neighboring locations separated by a state border share the same geography, climate, access to transportation, agglomeration 
benefits, access to specialized labor and supplies, etc. Moreover, Hagedorn et al. (2013) provide evidence that economic shocks do not stop when reaching a state border but tend to propagate smoothly in space. This implies that the underlying economic fundamentals are expected to evolve relatively similarly across counties bordering each other. The key feature that sets border counties apart is the difference in policies on the two sides of the border (unemployment benefit policies are set at the state level and apply to all counties within a state). These observations imply that absent state policy differences, the employment trends induced by fundamental economic shocks are expected to be similar across border counties in the same pair.

Thus, we begin our exploration of basic patterns in the data by simply assuming that the difference in benefit levels across two neighboring counties (determined at the state level) is not correlated with the difference in employment trends across the two counties. We considerably weaken this assumption in the formal analysis in subsequent Sections of the paper. Note that even the strong assumption underlying our exploration in this Section is much weaker than in existing work based on the border-county methodology as the policy change at the end of 2013 was exogenous to cross-sectional differences across U.S. states.

Following this logic, a sudden reversal of fortune experienced in 2014 by high benefit counties, evident in Figure 1, suggests that the cut in benefits led to a substantial increase in employment. After a long period of relative employment losses, the high benefit counties experienced a relative average employment gain of 0.50 percent in 2014 . As the average benefit duration before the policy change was 56.7 weeks in the high benefit counties and 47.6 weeks in the low benefit counties, the implied total employment gain from cutting benefits from an average level of 53 weeks to 25 weeks equals:

$$
\frac{53-25}{56.7-47.6} 0.50 \%=1.5 \%
$$

Thus, ignoring (for now) the potential aggregation issues, this simple calculation suggests a large increase in employment due to the cut in benefit durations. Similarly, for the labor force:

$$
\frac{53-25}{56.7-47.6} 0.43 \%=1.3 \%
$$




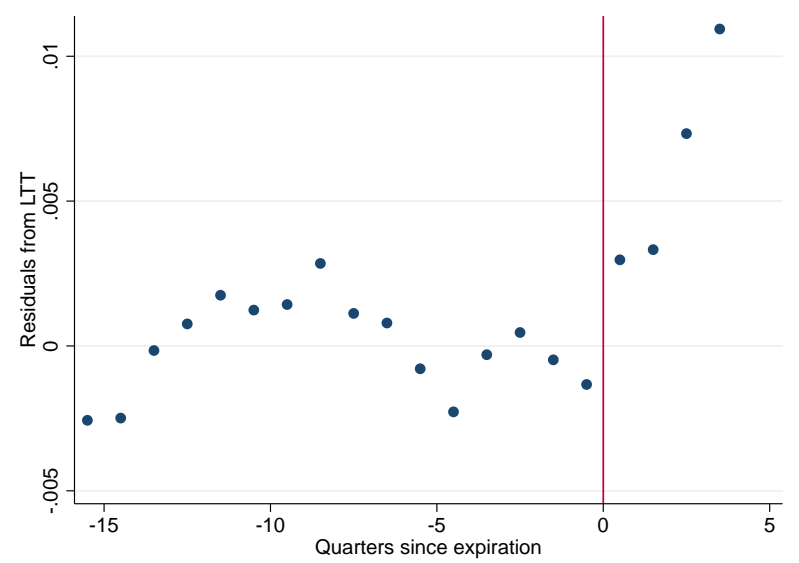

(a) Difference in Log Employment Residuals

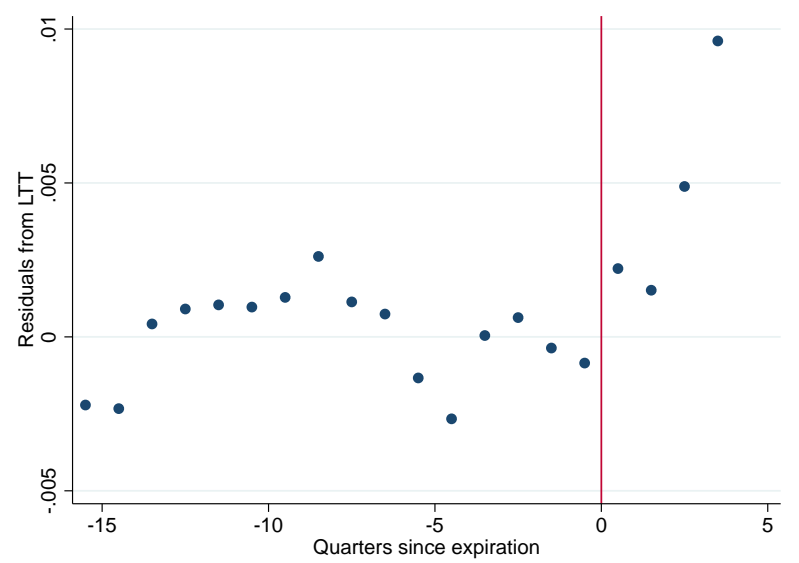

(b) Difference in Log Labor Force Residuals

Figure 3: Difference of residual employment and labor force between high and low benefit border counties (benefit differences measured in December 2013). Residuals constructed by removing fixed effects, linear time trends, and seasonality from the data for each county estimated on 2010/Q1-2013/Q4 period. Vertical line indicates EUC expiration.

In what follows we relax the common trend assumption underlying this simple experiment and allow for the possibility that unobserved trends could have led to high employment growth in border counties belonging to high benefit duration states even in the absence of the change in benefit durations. Specifically, we perform a more sophisticated econometric analysis that includes the estimation of the difference in trends between border counties in each pair.

To provide a simple visual verification that even the least flexible model of a trend ensures that the residual common trend assumption is satisfied, consider Figure 3, which plots the average difference in residuals between high and low benefit counties (as measured in December 2013) obtained by regressing over the 2010-2013 period county employment or labor force on a linear time trend, county fixed effects, and quarter dummies to remove seasonality. The residuals are close to zero through the end of 2013 - indicating the lack of important residual trends in the data (we will nevertheless use much more flexible models of trends below to guarantee this). Taking into account these linear trends, however, does not overturn our observations made based on Figure 1. Using the same estimates to construct the residuals in 2014 we observe, consistent with our previous reasoning, large positive residuals following the reform, indicating that the evolution of labor force and employment in 2014 was not the result of pre-existing trends. 


\section{Empirical Methodology I}

In this Section we describe the common methodology in the macro and labor literature for measuring the effect of the reform. ${ }^{9}$ This approach utilizes both pre- and post-reform information to measure the counterfactual trends in the labor force and employment that border counties would have experienced without a cut in benefits. We develop three distinct models of county-specific trends that differ in their flexibility and the ease of interpretation. Estimating these models reveals the effect of benefit duration on the difference in labor force or employment between border counties. At the end of this Section we show how these estimates can be aggregated to obtain an effect of the nation-wide change in benefit duration.

\subsection{Core of the Empirical Specification}

Our objective is to measure the effect of the cut of benefit durations in December 2013 on employment. The effect of this particular policy change on log employment $e_{i, t}$ in county $i$ in calendar quarter $t$ is captured by the coefficient $\alpha$ in the regression equation

$$
e_{i, t}=\alpha \mathcal{I}_{t \geq 2013 / Q 4} b_{i, t}+\epsilon_{i, t}
$$

where $\mathcal{I}_{t \geq 2013 / Q 4}$ is one for the policy change period starting in 2013/Q4 and is zero otherwise, $b_{i, t}$ is measured as the logarithm of available benefit duration, and the residual error term $\epsilon_{i, t}$ contains all other determinants of employment in county $i$ at time $t$. Below we develop alternative specifications of the stochastic process $\epsilon_{i, t}$, which include allowing for county fixed effects, county specific time trends, a very general factor model structure, etc. Estimating this process, e.g. a county specific time trend, requires to use data (on employment) prior to 2013/Q4. To ensure a consistent estimate of the trend, the specification then also has to control for the logarithm of benefit durations prior to 2013/Q4, of course, with a different coefficient $\kappa$, as the coefficient of interest $\alpha$ measures the effect of the 2014 exogenous policy change:

$$
e_{i, t}=\kappa \mathcal{I}_{t \leq 2013 / Q 3} b_{p, t}+\alpha \mathcal{I}_{t \geq 2013 / Q 4} b_{i, t}+\epsilon_{i, t} .
$$

\footnotetext{
${ }^{9}$ We apply an alternative methodology - the event study analysis - that uses only pre-reform data to estimate the counterfactual trends in Section 6.
} 
As explained above, we consider the difference in employment of a pair $p$ of counties $i$ and $j$ which border each other but belong to different states. For each border-county pair $p$, we difference Equation (4) between the two border counties $i$ and $j$ :

$$
\Delta e_{p, t}=\kappa \mathcal{I}_{t \leq 2013 / Q 3} \Delta b_{p, t}+\alpha \mathcal{I}_{t \geq 2013 / Q 4} \Delta b_{p, t}+\Delta \epsilon_{p, t},
$$

where $\Delta$ is the difference operator over counties in the same pair. More specifically, if counties $i$ and $j$ are in the same border-county pair $p$, then $\Delta e_{p, t}=e_{p, i, t}-e_{p, j, t}$ and $\Delta b_{p, t}=b_{p, i, t}-b_{p, j, t}$.

This is the core specification we use throughout this section of the paper. We augment it with different models of the stochastic process $\epsilon_{i, t}$ that we develop next. It is important to keep in mind that the effects of shocks or policies that affect these counties symmetrically are differenced out since our estimates are based on the differences across border counties.

\subsection{Baseline Empirical Model and Identification}

Our benchmark specification represents the standard approach in the literature, which allows for permanent and temporary differences in employment $e$ across counties caused by, e.g., permanent differences in tax policies across states they belong to and it also contains county specific employment trends. In addition, we control for aggregate time effects:

$$
\epsilon_{i, t}=\gamma_{i} t+\phi_{i}+\delta_{t}+\nu_{i, t}
$$

where $\gamma_{i}$ is the county specific time trend of county $i, \phi_{i}$ is a county fixed effect and $\delta_{t}$ is a time dummy. Differencing the error term across counties in the same pair, we obtain

$$
\Delta_{p} \epsilon_{p, t}=\gamma_{i} t-\gamma_{j} t+\phi_{i}-\phi_{j}+\Delta_{p} \nu_{p, t}
$$

Our baseline specification can then be written as

$$
\Delta e_{p=(i, j), t}=\kappa \mathcal{I}_{t \leq 2013 / Q 3} \Delta b_{p, t}+\alpha \mathcal{I}_{t \geq 2013 / Q 4} \Delta b_{p, t}+\gamma_{i} t-\gamma_{j} t+\phi_{i}-\phi_{j}+\nu_{p, t}
$$

Note that since we have several years of pre-reform data we can identify a pair-specific trend, ${ }^{10}$

\footnotetext{
${ }^{10}$ Note that we estimate trends and fixed effects at the county level and refer to the difference across counties within a pair of those trends as "pair-specific" trend.
} 
which would not be possible if we had only one pre-reform and one post-reform observation for every county pair. This data-rich environment thus allows us to precisely estimate the pre-existing trend implying that differences in trend employment do not bias our results. The identification assumption for the effects of benefits on employment is thus conditional on the pair-specific trend, the pair-specific fixed effect and the time effect:

$$
\operatorname{Corr}\left(\mathcal{I}_{t \geq 2013 / Q 4} \Delta b_{p, t}, \nu_{p, t}\right)=0
$$

As in any difference-in-differences analysis, the parameter of interest $\alpha$ is identified off the change in benefits when EUC08 expires. The expiration of benefits is exogenous with respect to cross-sectional differences in county employment. To understand what assumption (9) rules out, imagine for a moment that our dataset contained just two counties $i$ and $j$ in a pair $p$ where county $i$ has higher benefits at the end of 2013 than county $j$. In this case our estimate would not recover the true effect of benefits on employment if county $i$ would have had higher employment growth (relative to the estimated trends) than county $j$ even in the absence of the benefit cut. In this case we would attribute some of the differences in employment growth to the cut in benefits although not all of the employment differences are related to benefits.

However, our dataset contains not just one county pair but 1,175 of such pairs. The identifying assumption then rules out that the higher benefit counties would have had on average higher employment growth in the absence of the policy reform and does not rule it out for every individual pair. It is important to recognize that this assumption is conditional on using pair-specific trends to remove differences in trends between counties in a pair. The figures in Section 2.2 above lend support to the identifying assumption as, prior to the policy change, high benefit counties did not show on average faster employment growth than their low benefit counterparts in the border pair. Instead, one clearly sees a sudden rise in employment growth just when benefits were cut at the turn of 2014, but no sign of recovering, say, mechanically due to mean reversion, prior to the benefit expiration. Moreover, as discussed above, with the exception of the expiration of EUC08, there were no policy changes or other developments that could have plausibly induced the co-movement between the size of the benefit cut and the subsequent employment growth across border counties. Finally, it is also important to note that to violate the identifying assumption, the higher average employment growth in the 
higher benefit counties in the absence of the experiment would have to be purely mechanical and not behavioral since counties and states could not select into the experiment based on their employment in December 2013 nor on their expected employment growth in 2014. That means, that the exogeneity of the program rules out a version of a behavioral Ashenfelter's "dip."

\subsection{Factor Models}

An alternative modeling strategy for heterogeneous county-level employment trends formalizes the insight that these trends are induced by the differences in exposure of counties to various common aggregate disturbances. The differences in exposure may arise due to, e.g., differences in sectoral composition, which may themselves be a consequence of heterogeneity in the host of other state- and county-level policies. We therefore decompose the error term in Equation (5) as

$$
\Delta \epsilon_{p, t}=\left(\lambda_{i}^{\prime}-\lambda_{j}^{\prime}\right) F_{t}+\nu_{p, t}
$$

where $\lambda_{i}, \lambda_{i}(r \times 1)$ are vectors of county-specific factor loadings and $F_{t}(r \times 1)$ is a vector of time-specific common factors. Note that this general notation nests additive county-level fixed effects, county-specific time trends, and aggregate time effects. ${ }^{11}$ Our baseline specification can then be written as

$$
\Delta e_{p, t}=\alpha \mathcal{I}_{t \geq 2013 / Q 4} \Delta b_{p, t}+\left(\lambda_{i}^{\prime}-\lambda_{j}^{\prime}\right) F_{t}+\nu_{p, t}
$$

What remains to be done is to specify the aggregate factors. To this aim we pursue two approaches.

\subsubsection{Latent Factors Model}

The first approach treats the factors as being unobserved so that both the factors and factor loadings are parameters to be estimated. Specifically, we use an interactive-effects estimator that was shown in Bai (2009) to achieve consistency and proper inference in a panel data

\footnotetext{
${ }^{11}$ Suppose there are two factors in $F_{t}=\left[\begin{array}{c}1 \\ \xi_{t}\end{array}\right]$ (among others) with associated loadings $\lambda_{i}=\left[\begin{array}{c}\psi_{i} \\ 1\end{array}\right]$, $\lambda_{j}=\left[\begin{array}{c}\psi_{j} \\ 1\end{array}\right]$, yielding $\Delta \epsilon_{p, t}=\left(\lambda_{i}^{\prime}-\lambda_{j}^{\prime}\right) F_{t}+\nu_{p, t}=\psi_{i}-\psi_{j}+\xi_{t}+\nu_{p, t}$, i.e., county fixed effects and a time effect.
} 
context, such as ours. ${ }^{12}$

Note that the interactive effects model, in addition to additive time and county fixed effects, allows for a very flexible model of the heterogeneous time trends at the county level. To implement this estimator, we need to specify the number of factors. Bai and $\mathrm{Ng}$ (2002) have shown that the number of factors in pure factor models can be consistently estimated based on the information criterion approach. Bai (2009) shows that their argument can be adapted to panel data models with interactive fixed effects (see Appendix I).

Note that since this estimator involves estimating the values of aggregate factors in every period, to predict counterfactual trends it is necessary to use the post-reform data in estimation. The factor loadings, however, are mainly identified from the period before the reform in 2013/Q4 as our estimation sample starts in 2005/Q1.

The flexibility of this modeling approach comes at the cost of not being able to assign a clear economic interpretation to estimated factors. To the extent that we are only interested in an unbiased estimate of the effects of benefit on employment only, however, the interpretability of estimated factors is not a relevant concern.

\subsection{2 "Natural" Factors Model}

While the latent factor approach is very flexible, the selection of factors is based on statistical rather than economic considerations. To provide a more economically grounded model, we consider a hybrid of the previous two models:

$$
\epsilon_{i, t}=\gamma_{i} t+\phi_{i}+\delta_{t}+\lambda_{i}^{\prime} F_{t}+\nu_{i, t}
$$

The key difference to the latent factor models is that now we select a set of observed aggregate factors to include in $F_{t}$ that economic analysis suggests are important in inducing heterogeneous trends across counties. Thus, with the appropriate selection of the aggregate factors, this specification approaches the flexibility of the latent factor model while inheriting the transparency of the baseline specification.

\footnotetext{
${ }^{12}$ Gobillon and Magnac (2015) establish the superior performance of the interactive effects estimator relative to alternatives methods.
} 


\subsection{Aggregation of Local Employment Effects}

Our estimate of the effect of unemployment benefit extensions on employment is based on the difference across border counties. It is desirable to be able to use the resulting coefficient to predict the effect of a nation-wide extension. A potential concern is that when some states extend benefits more than others, economic activity may reallocate to states with, say, lower benefits. This reallocation is picked up by our estimates but will be absent when the policy is changed everywhere. Our results in Section 4.2.1 below alleviate such concerns. First, we find large negative effects of unemployment benefit extensions on employment in sectors commonly considered non-tradable and thus not subject to reallocation. Second, we find that unemployed workers do not change the strategy of which county to look for work in response to changes in benefits. Building on these insights, we show in Appendix II that we can use the estimates obtained at the county level to compute the change in US employment due to the cut in benefits in a model where each county is an open economy in the (closed) US economy and the labor market in each county is governed by a Mortensen-Pissarides search and matching model. Each county produces (and consumes) a nontradable and a tradable good. Both sectors, the one producing the tradable good and the one producing the nontradable one, operate in the same labor market and are subject to the same labor market frictions. We then show that our elasticity for the employment response at the county level can be used at the aggregate level as well.

Specifically, due to the absence of reallocation and mobility caused by a change in benefits we can estimate Equation (5) in the data and recover the coefficient of interest $\alpha$ and use it to compute the percentage increase in U.S. employment in 2014 that is caused by the cancellation of extended benefits as

$$
\pi^{E}=\alpha \sum_{\text {All U.S. states } s}\left(b_{s}^{2014}-b_{s}^{2013}\right) \frac{E_{s}^{2013}}{E_{U S}^{2013}},
$$

where $b_{s}^{2013}$ denotes the logarithm of the number of weeks of benefits available in state $s$ in December 2013 (just prior to the policy change), $b_{s}^{2014}$ is the logarithm of the number of weeks

of benefits available in state $s$ in $2014, E_{s}^{2013}$ is employment in state $s$ in December 2013 and $E_{U S}^{2013}$ is aggregate U.S. employment in December 2013. The corresponding gain in the total 
number of employed then equals

$$
\Delta^{E}=\frac{\pi^{E} \times E_{U S}^{2014}}{1+\pi^{E}}
$$

where $E_{U S}^{2014}$ refers to U.S. employment in December 2014.

Estimating Equation (5) but replacing the difference in the log of the number of employed in the border county pair on the left hand side with the corresponding difference in the log of the number of labor force participants allows as to compute the effect of the cut in benefits on the labor force. Using the analogues to Equations (13) and (14), we can then measure the percentage increase in the labor force $\pi^{L}$ and the increase in the number of labor force participants $\Delta^{L}$ as a consequence of the policy reform.

\subsection{Placebo Reform Analysis}

In addition to measuring the effects of the actual cut in benefit duration in December 2013, we also re-estimate each empirical model in the paper to assess the effects of a placebo reform. Specifically, we counterfactually assume that benefit durations were cut nationwide starting in the second quarter of 2010. We choose this date for the placebo reform for two reasons. First, there were no actual cuts in benefit duration in 2010, meaning that the counterfactual reform was a true placebo. Second, the second quarter of 2010 represented a turning point in the dynamics of aggregate unemployment, which declined significantly for the first time since the onset of the Great Recession. ${ }^{13}$

The objective of estimating the effects of the counterfactual placebo reform is to verify whether the turning point of employment dynamics in 2013/2014 of high relative to low benefit countries was indeed caused to a large degree by the exogenous cut in benefits in December 2013 as opposed to being the result of an employment adjustment which would have happened anyway and with the simultaneous cut in benefit durations being a pure coincidence. To the extent that the analysis of a placebo reform reveals that the employment in high benefit counties did not grow faster (or indeed grew even slower) than in their border counties in lower benefit duration states, it strengthens the case that the co-movement of the benefit cuts

\footnotetext{
${ }^{13}$ In practice, we found that performing the placebo experiment at other points in time leads to the same conclusions.
} 
Table 2: Unemployment Benefit Extensions, Employment, and Labor Force.

Benchmark Specification.

\begin{tabular}{|c|c|c|c|c|}
\hline & \multicolumn{2}{|c|}{ Actual Reform } & \multicolumn{2}{|c|}{ Placebo Reform } \\
\hline & Employment & Labor Force & Employment & Labor Force \\
\hline Weeks of Benefits & $\begin{array}{c}\mathbf{- 1 . 9 0} \\
(0.000)\end{array}$ & $\begin{array}{c}\mathbf{- 0 . 8 6} \\
(0.000)\end{array}$ & $\begin{array}{c}1.72 \\
(0.050)\end{array}$ & $\begin{array}{c}\mathbf{2 . 6 8} \\
(0.000)\end{array}$ \\
\hline
\end{tabular}

Note - All coefficients are multiplied by 100. Bold font denotes significance at a $95 \%$ level based on bootstrapped p-values in parentheses.

and the 2014 employment boom was not coincidental.

\section{Unemployment Benefit Extensions, Employment and Labor Force}

\subsection{Empirical Methodology I, Specification I - Baseline. Findings.}

Table 2 contains the results of the estimation of the effect of unemployment benefit duration on employment using the baseline specification in Equation (8) for the period 2010-2014. We find that changes in unemployment benefits have a large and statistically significant ${ }^{14}$ effect on employment: a 1 percent drop in benefit duration increases employment by 0.019 log point. ${ }^{15}$ We can also use Equation (8) with labor force on the left hand side to estimate the percentage change in the labor force attributable to the cancellation of policy. Estimating this equation, we find that a 1 percent drop in benefit duration increases the labor force by 0.0086 log points.

The results of estimating the effects of a placebo reform are very different. They indicate that without the actual cut in benefit duration, employment and the labor force in high benefit counties grew significantly slower than in the lower benefit duration counties across the state border. Inspecting Figure 2 makes this finding not very surprising as there is only one turning point in the dynamics of relative employment and labor force between border counties in 2014 but not in earlier years. We conclude that both in 2010 and 2014 high benefit counties did not experience higher employment growth than low benefit counties for reasons unrelated to

\footnotetext{
${ }^{14}$ To take into account the potential correlation in the residuals, standard errors in this and other specification in the paper are computed using block-bootstrap following Bertrand et al. (2004).

${ }^{15}$ This is slightly larger but comparable to the corresponding effect estimated in Hagedorn et al. (2013).
} 
benefits. The difference between 2010 and 2014, however, is that in 2014 benefits were cut whereas in 2010 such a cut did not happen. As a result, we find an employment boom in 2014 but not in the placebo reform. ${ }^{16}$

\subsection{Implications for Aggregate Employment and Labor Force}

\subsubsection{Evidence on Reallocation and Mobility}

As discussed above, the degree to which one can rely exclusively on our local estimates of the effects of unemployment benefit extensions to predict the effects of a nation-wide extensions depends on whether local benefit extensions induce a spatial reallocation of economic activity. In this section we document the extent of such reallocation.

If the local change in employment was driven to an important degree by reallocation, we would expect that benefit extensions have a larger effect on the tradable sector, which can reallocate, than on the non-tradable, which can reallocate to a much lesser degree. Thus, if there is substantial reallocation of economic activity in response to local changes in benefit duration, we would expect to find an increase in the ratio of employment in non-tradable to tradable sectors in the relatively high benefit duration counties. To assess this possibility, we apply our border-county empirical methodology to measure the change in employment in sectors producing output that is plausibly non-tradable across states, such as retail or food services, to the change in employment in tradable sectors. We find that a rise in benefit duration has no significant effect (a coefficient of -0.00267 with a p-value of 0.23 ) on the relative employment in the two sectors, implying that the null hypothesis of no reallocation induced by benefit extensions cannot be rejected in the data.

In addition, Hagedorn et al. (2015) use the Nielsen Consumer Panel Data to measure the responsiveness of cross state border shopping to changes in unemployment benefit generosity. Their results indicate that this effect is also negligible.

\footnotetext{
${ }^{16}$ Our motivation for considering border counties as a unit of analysis was the fact that these locations are relatively small and share common exposure to aggregate shocks which makes it more likely that the common trend assumption is satisfied. While we include all border county pairs in the analysis, we can also select subsets of border counties where this is even more likely to be the case. This does not alter the results, however. For example, restricting the sample to only small counties that account for less than $15 \%$ of their state's employment yields coefficients of -1.95 and -0.86 for employment and labor force, respectively. Similarly, limiting the analysis only to closely integrated counties in the same Core-Base Statistical Area yelds respective estimated coefficients of -2.08 and -1.42 . Despite smaller samples, the coefficients remain highly statistically significant.
} 
Another potential reallocation effect arises because households may live in different states than where they work. Note that this type of worker reallocation would bias even our local estimates if the households systematically change their job search behavior in response to changes in unemployment benefits. For example, suppose households search in states with less generous benefits to take advantage of a higher job-finding rate. As county employment is measured based on the place of residence and not on the basis of the location of the job, our estimate of the effect of benefit extensions on employment would be biased downwards, since households residing in high benefit counties would face a higher job-finding rate, which would translate into higher employment in their county of residence (despite them actually working in the neighboring county). To investigate whether this is the case, we use direct empirical evidence on where people work relative to where they live. Specifically, we use data from the American Community Survey (ACS) from 2005-2013. The ACS is an annual $1 \%$ survey of households in the United States conducted by the Census Bureau. The survey contains information on the county of residence of households and the state of employment. The survey is representative at the Public Use Micro Area level - a statistical area that has roughly 100,000 residents (and thus also for counties with more than 100,000 residents). We compute the share of households in border counties who work in the neighboring state. We can then examine how this share of cross state border workers responds to changes in benefits across states. Using the difference-in-difference estimator, we find a very small and statistically insignificant coefficient on weeks of benefits available of 0.0107 (p-value 0.219). This evidence implies that workers' search behavior does not respond significantly to changes in local unemployment benefit duration.

\subsubsection{Aggregate Implications of Baseline Empirical Results}

The foregoing results that changes in benefit durations induce neither reallocation of economic activity nor worker mobility imply (using the model laid out in Appendix II) that we can rely on our estimate based on border counties to derive the implications for employment for the aggregate U.S. economy. In particular, our estimate implies that the drop in benefit duration 
led to a percentage increase in aggregate employment of

$$
\pi^{E}=\underbrace{\alpha}_{-0.0190} \underbrace{\sum_{\text {All U.S. states } s}\left(b_{s}^{2014}-b_{s}^{2013}\right) \frac{E_{s}^{2013}}{E_{U S}^{2013}}}_{-0.799}=0.015,
$$

that is U.S. employment increased by 1.5 percent due to the cut of benefit durations. The corresponding gain in the total number of employed then equals

$$
\Delta^{E}=\frac{0.015 \times E_{U S}^{2014}}{1+0.015}=2,074,100
$$

Similarly, the percentage change in the size of the labor force in the U.S. due to the cancellation of benefits equals

$$
\pi^{L}=\underbrace{\alpha^{L}}_{-0.0086} \underbrace{\sum_{\text {All U.S. states } s}\left(b_{s}^{2014}-b_{s}^{2013}\right) \frac{L_{s}^{2013}}{L_{U S}^{2013}}}_{-0.801}=0.007,
$$

and the corresponding increase in the size of the labor force is

$$
\Delta^{L}=\frac{\pi^{L} \times L_{U S}^{2014}}{1+\pi^{L}}=1,119,500
$$

Thus, more than half of the increase in employment was due to the increase in the labor force as a result of the reduction of benefit duration. The remaining increase corresponds to a decrease in the number of unemployed by $954,600=2,074,100-1,119,500$. Our analysis thus shows that the dominant impact of the benefit cut on employment was not driven by a contraction in the labor force - unemployed dropping out of the labor force because they were no longer entitled to benefits - but instead by those previously not participating in the labor market deciding to enter the labor force.

It is also interesting to note that the existing empirical literature has mainly attempted to measure the "micro" effect of unemployment benefit duration on search intensity and job acceptance decisions of individual workers. Hagedorn et al. (2014) find these effects to be very small, confirming the sentiment in the literature. Clearly, this micro effect is zero for those out-of-labor force who were entitled to benefits neither in 2013 nor in 2014. Yet, it was predominantly movements from out-of-labor force that drove the rise in employment in 2014. 
Table 3: Unemployment Benefit Extensions, Employment, and Labor Force. Interactive Effects Model.

\begin{tabular}{|c|c|c|c|c|}
\hline & \multicolumn{2}{|c|}{ Actual Reform } & \multicolumn{2}{|c|}{ Placebo Reform } \\
\hline & Employment & Labor Force & Employment & Labor Force \\
\hline Weeks of Benefits & $\begin{array}{c}\mathbf{- 2 . 3 3} \\
(0.000)\end{array}$ & $\begin{array}{c}-\mathbf{1 . 2 3} \\
(0.000)\end{array}$ & $\begin{array}{c}\mathbf{1 . 2 2} \\
(0.030)\end{array}$ & $\begin{array}{c}\mathbf{1 . 9 4} \\
(0.010)\end{array}$ \\
\hline Number of Factors & 4 & 4 & 4 & 4 \\
\hline
\end{tabular}

Note - All coefficients are multiplied by 100. Bold font denotes significance at a $95 \%$ level based on bootstrapped p-values in parentheses.

Presumably this happened due to a large "macro" effect of the benefit cut on job creation. It is then the availability of jobs that drew non-participants back into the labor force, as is consistent with the standard prediction of labor search models.

\subsection{Empirical Methodology I, Specification II - Interactive Effects Model. Findings.}

Table 3 contains the results of this estimation of the effect of unemployment benefit duration on employment and labor force using the interactive effects specification of the factor model in Equation (11). This is the most flexible, albeit the least transparent, model of underlying county-level employment and labor force trends that we consider.

Relative to a more restrictive baseline specification, the results of estimating this model reveal slightly larger effects of unemployment benefit durations. Specifically, the estimates imply that a 1 percent drop in benefit duration increases employment by 0.0233 log points and the labor force by 0.0123 log points. Similar to the baseline specification, these estimates also imply that more than half of the increase in employment was due to the increase in the labor force as a result of the reduction of benefit duration. 
Table 4: Unemployment Benefit Extensions, Employment, and Labor Force.

"Natural" Factors Model.

\begin{tabular}{|c|c|c|c|c|}
\hline & \multicolumn{2}{|c|}{ Actual Reform } & \multicolumn{2}{|c|}{ Placebo Reform } \\
\hline & Employment & Labor Force & Employment & Labor Force \\
\hline Weeks of Benefits & $\begin{array}{c}\mathbf{- 1 . 4 4} \\
(0.000)\end{array}$ & $\begin{array}{c}\mathbf{- 0 . 5 8} \\
(0.000)\end{array}$ & $\begin{array}{c}\mathbf{1 . 3 8} \\
(0.020)\end{array}$ & $\begin{array}{c}2.27 \\
(0.000)\end{array}$ \\
\hline
\end{tabular}

Note - All coefficients are multiplied by 100. Bold font denotes significance at a $95 \%$ level based on bootstrapped p-values in parentheses.

\subsection{Empirical Methodology I, Specification III - "Natural" Factors Model. Findings.}

We now consider the "hybrid" factor model specification where we include "natural" factors in addition to standard controls in the baseline specification such as fixed and time effect as well as pair-specific trends. We consider three aggregate time series for this purpose. ${ }^{17}$ The first one represents the price of oil. There was a sharp decline in the price of oil in the second half of 2014 which likely had a heterogeneous impact on counties and the exposure of counties to the booming oil industry in 2013 might have been correlated with pre-reform benefit duration. The second series represents aggregate employment in the construction sector. The construction sector was dramatically affected by the recession with considerable spatial heterogeneity which might have been also correlated with benefit duration across states. Finally, we include an index of monetary policy. The specific series we use - the reserve balances with the Fed system - shows a clear structural break in early 2014 and might imply spatially heterogeneous impacts on the availability of credit.

Table 4 contains the results of this estimation of the effect of unemployment benefit duration on employment using the "natural" factors specification in Equation (12). Similar to the results from the two alternative specifications described above, we find that changes in unemployment benefits have a large and statistically significant effect on employment: a 1 percent drop in benefit duration increases employment by 0.0144 log point. We can again use

\footnotetext{
${ }^{17}$ All "natural" factor series ("Crude Oil Prices: West Texas Intermediate (WTI) - Cushing, Oklahoma" [DCOILWTICO], "All Employees: Construction" [USCONS], "Total Reserve Balances Maintained with Federal Reserve Banks" [RESBALNS]) retrieved from FRED, Federal Reserve Bank of St. Louis https://research.stlouisfed.org/fred2/, May 27, 2015.
} 
Equation (12) with labor force on the left hand side to estimate the percentage change in the labor force attributable to the cancellation of policy. Estimating this equation, we find that a 1 percent drop in benefit duration increases the labor force by 0.0058 log points.

\section{Unemployment Benefit Extensions and QCEW Payroll Employment}

The traditional approach, at least in the macroeconomics literature, to measuring the aggregate effects of policies on employment, defines the latter variable as including all individuals who did any work for pay or profit during a given week. For example, when measuring the aggregate effects, the literature usually does not draw a distinction whether the increase in employment was due to more individuals becoming employees or starting their own businesses. The object of interest is the change in the total number of individuals supplying labor in the market in response to a policy change. This is the established definition of employment adopted by the Current Population Survey and it corresponds to the measure of employment used so far in this paper. The disadvantage of this measure of employment is that some components of employment have to be measured through surveys that are subject to sampling error.

A more narrow notion of employment can, however, be measured through administrative records. These data are called Quarterly Census of Employment and Wages (QCEW) and represent the count of jobs for which a paycheck subject to a UI tax was issued. Due to the nature of these data, this employment measure counts the number of jobs rather than the number of individuals with at least one job so that the same individual may be counted multiple times if he or she receives payments from multiple employers. Moreover, the data excludes most jobs not subject to the UI tax, such as self employed workers, unpaid family workers or employees of schools affiliated with religious organizations, railroad employees, etc. as well as jobs excluded for other reasons, such as employees of national security agencies.

It is well documented that these two measures of employment often diverge significantly even after accounting for the differences in coverage. ${ }^{18}$ Of a particular concern to the period we study is the sharp rise in non-traditional employment, or what has become known as the

\footnotetext{
${ }^{18}$ See Hagedorn and Manovskii (2011) for the discussion and additional references.
} 
Table 5: Unemployment Benefit Extensions and QCEW Payroll Employment

\begin{tabular}{lcc}
\hline Specification & Actual Reform & Placebo Reform \\
\hline Benchmark & $\mathbf{- 1 . 0 0}$ & $\mathbf{1 . 0 0}$ \\
& $(0.050)$ & $(0.030)$ \\
Natural Factors & $\mathbf{- 1 . 4 1}$ & 0.78 \\
& $(0.020)$ & $(0.200)$ \\
Interactive Effects & $\mathbf{- 1 . 2 1}$ & $\mathbf{1 . 5 9}$ \\
& $(0.030)$ & $(0.050)$ \\
\hline
\end{tabular}

Note - All coefficients are multiplied by 100. Bold font denotes significance at a $90 \%$ level based on bootstrapped p-values in parentheses.

rise of "1099 economy" (the IRS form 1099-MISC must be submitted by all "employers" who pay someone $\$ 600$ or more a year in nonemployee compensation). Dourado and Koopman (2015) document a sharp rise in the number of these forms submitted to the IRS in recent years. For example, an Uber driver would be paid this way. He or she will be classified as being employed according to the CPS definition but will not appear in the QCEW data. An additional complication presented by this rapid ongoing change in the labor market is that an Uber driver may not even classify himself as being self-employed but to consider himself as being employed by Uber when replying to the survey. This makes it challenging to interpret the data on self-employment and to use it in conjunction with QCEW data to obtain the picture of total employment changes.

Nevertheless, as QCEW data refer to a well defined segment of employment and are not affected by the sampling error, it appears interesting to assess the effects of the cut in benefits on payroll counts as measured by the QCEW. Accordingly, we repeat the entire analysis above using these data. Table 5 contains the results. We find that these data also reveal a significant positive impact of the reduction in benefit duration on payroll employment. Specifically, across the methodologies we consider, a 1 percent drop in benefit duration significantly increases payroll counts by between 1 and 1.4 log points. These effects are slightly smaller than those obtained using the total employment measures. The foregoing discussion illustrates the difficulties in interpreting this difference. For example, it might be that non-traditional employment was particularly sensitive to the cut in benefits. Alternatively, it might be that 
holders of several part-time jobs secured full-time employment as a result of increased job availability following the EUC08 expiration which would be recorded as a decline in the number of jobs in the QCEW. To put even these smaller estimates into perspective, consider the implied aggregate employment changes using the smallest estimate based on QCEW data across all specifications we consider. This estimate implies that the drop in benefit duration led to a percentage increase in aggregate payroll employment of

$$
\pi^{E}=\underbrace{\alpha}_{-0.0100} \underbrace{\sum_{\text {All U.S. states } s}\left(b_{s}^{2014}-b_{s}^{2013}\right) \frac{E_{Q C E W, s}^{2013}}{E_{Q C E W, U S}^{2013}}}_{-0.803}=0.008,
$$

that is U.S. payroll employment increased by 0.8 percent due to the cut of benefit durations. The corresponding gain in the total number of employed on payrolls then equals

$$
\Delta^{E}=\frac{0.008 \times E_{Q C E W, U S}^{2014}}{1+0.008}=1,105,289 .
$$

This accounts for 36\% of the growth in payroll employment in 2014.

Estimating the effects of a placebo reform on QCEW data once again indicate that without the actual cut in benefit duration, payroll employment and the labor force in high benefit counties grew slower than in the lower benefit duration counties across the state border.

\section{Empirical Methodology II: Event Study Analysis}

A different methodological approach we use to measure the impact of the cut in benefit durations on labor force and employment is based on an event study analysis. The event study approach is widely used in economics and finance (see MacKinlay (1997) for a survey). The idea of an event analysis is simple. The normal or expected evolution of e.g. employment is estimated using data before the event. The pre-event estimate is then used to compute the "unusual" changes in employment as the deviation of the actual post-event evolution of employment from its normal behavior that would have been expected in the absence of the event. Thus, the post-event normal behavior of employment is computed using the estimates from the pre-event estimation window without conditioning on the event taking place.

In our application, the event is the cut in benefit durations at the very end of Decem- 
ber 2013. The pre-event estimation window includes the years 2005-2013 and the post-event window is the year 2014 .

The key step of the event study methodology is to choose a rich model of the normal evolution of employment that fits the pre-event data as well as possible and can be used to accurately forecast its post-event evolution. Note that in an event analysis or a forecasting analysis including (potentially) endogenous variables on the RHS is not problematic since we are not interested in the estimated coefficients but we want to use all available information to accurately predict the (counterfactual) normal evolution of employment in 2014. The only restriction is that the forecast cannot rely on post-event variables that are endogenous with respect to the event itself. Therefore, the model we use to describe the normal evolution of employment in county $i$ prior to 2014 features a cubic time trend and 4 lags of employment:

$$
e_{i, t}=\gamma_{1 i} t+\gamma_{2 i} t^{2}+\gamma_{3 i} t^{3}+\phi_{i}+\delta_{t}+\mu_{1} e_{i, t-1}+\mu_{2} e_{i, t-2}+\mu_{3} e_{i, t-3}+\mu_{4} e_{i, t-4}+\nu_{i, t} .
$$

As before, we difference this equation between neighboring counties $i$ and $j$ in a pair $p$ :

$$
\begin{aligned}
\Delta_{p} e_{p, t} & =\gamma_{1 i} t-\gamma_{1 j} t+\gamma_{2 i} t^{2}-\gamma_{2 j} t^{2}+\gamma_{3 i} t^{3}-\gamma_{3 j} t^{3}+\phi_{i}-\phi_{j} \\
& +\mu_{1} \Delta_{p} e_{p, t-1}+\mu_{2} \Delta_{p} e_{p, t-2}+\mu_{3} \Delta_{p} e_{p, t-3}+\mu_{4} \Delta_{p} e_{p, t-4}+\nu_{p, t}
\end{aligned}
$$

Denote the parameter values of this model estimated on the pre-event window with a hat. These estimates can then be used to describe the expected evolution of the difference in employment across counties in a pair in 2014 without conditioning on the cut in benefit duration taking place:

$$
\begin{aligned}
E\left(\Delta_{p} e_{p, t}\right) & =\left(\hat{\gamma}_{1 i}-\hat{\gamma}_{1 j}\right) t+\left(\hat{\gamma}_{2 i}-\hat{\gamma}_{2 j}\right) t^{2}+\left(\hat{\gamma}_{3 i}-\hat{\gamma}_{3 j}\right) t^{3}+\left(\hat{\phi}_{i}-\hat{\phi}_{j}\right) \\
& +\hat{\mu}_{1} \Delta_{p} e_{p, t-1}+\hat{\mu}_{2} \Delta_{p} e_{p, t-2}+\hat{\mu}_{3} \Delta_{p} e_{p, t-3}+\hat{\mu}_{4} \Delta_{p} e_{p, t-4}
\end{aligned}
$$

where the expected post-reform evolution of employment is computed recursively.

The unusual or unexpected component of the dynamics of the difference in border county 
Table 6: Unemployment Benefit Extensions, Employment, and Labor Force.

Event Study.

\begin{tabular}{|c|c|c|c|}
\hline & \multicolumn{2}{|c|}{ LAUS Data } & QCEW Data \\
\hline & Employment & Labor Force & Employment \\
\hline Weeks of Benefits & $\begin{array}{c}\mathbf{- 1 . 8 3} \\
(0.000)\end{array}$ & $\begin{array}{c}\mathbf{- 1 . 0 8} \\
(0.010)\end{array}$ & $\begin{array}{c}\mathbf{- 2 . 3 6} \\
(0.000)\end{array}$ \\
\hline
\end{tabular}

Note - All coefficients are multiplied by 100 . Bold font denotes significance at a $95 \%$ level based on bootstrapped p-values in parentheses.

employment, $\Delta_{p} e_{p, t}$, at post-event date $t$ is denoted $\hat{\epsilon}_{p, t}^{*}$ and equals

$$
\begin{aligned}
\hat{\epsilon}_{p, t}^{*} & =\Delta_{p} e_{p, t}-E\left(\Delta_{p} e_{p, t}\right) \\
& =\Delta_{p} e_{p, t}-\left[\left(\hat{\gamma}_{1 i}-\hat{\gamma}_{1 j}\right) t+\left(\hat{\gamma}_{2 i}-\hat{\gamma}_{2 j}\right) t^{2}+\left(\hat{\gamma}_{3 i}-\hat{\gamma}_{3 j}\right) t^{3}+\left(\hat{\phi}_{i}-\hat{\phi}_{j}\right)\right. \\
& \left.+\hat{\mu}_{1} \Delta_{p} e_{p, t-1}+\hat{\mu}_{2} \Delta_{p} e_{p, t-2}+\hat{\mu}_{3} \Delta_{p} e_{p, t-3}+\hat{\mu}_{4} \Delta_{p} e_{p, t-4}\right]
\end{aligned}
$$

where $\Delta_{p} e_{p, t}$ is the actual observed employment difference in a quarter $t$ in 2014 .

Finally, to assess the impact of the benefit duration cut on the unusual dynamics of employment in 2014, we estimate

$$
\hat{\epsilon}_{p, t}^{*}=\alpha\left(\Delta_{p} b_{p, t}-\Delta_{p} b_{p, 2013 / Q 4}\right)
$$

As before, we compute standard errors via block bootstrap and take into account that our forecast $\Delta_{p} e_{p, t}$ is an estimated outcome subject to forecast error. ${ }^{19}$

\subsection{Empirical Findings from the Event Study Analysis}

Table 6 contains the results of this estimation of the effect of unemployment benefit duration on employment and the labor force using an event study methodology. Both LAUS and QCEW data imply a large positive impact of the cut in benefit duration on the respective measures of employment. Similar to the preceding findings based on different methodologies, the results

\footnotetext{
${ }^{19}$ Specifically, in each bootstrap replication, to construct the county forecast $\tilde{e}_{i, t}$, we take the fitted value predicted by the pre-event regression, $\hat{e}_{i, t}$ and add in forecast error (to be consistent with the magnitude of errors from the forecasting regression, we do this by sampling from the residuals of the pre-event regression in Eq. 23). We then difference across pairs to generate $E\left(\Delta_{p} \tilde{e}_{p, t}\right)$.
} 
of the event analysis imply that approximately one half of this increase in employment was due to the increase in the labor force as a result of the reduction in benefit duration.

\section{Conclusion}

In this paper we measure the effect of unemployment benefit extensions on employment and the labor force. We exploit the variation induced by the decision of the U.S. Congress in December of 2013 to abruptly stop all federal unemployment benefit extensions. The particular usefulness of this policy change for understanding the employment effects of benefit extensions stems from the fact that the policy change at the national level was exogenous to economic conditions of individual states.

Following the aftermath of the Great Recession, by December 2013 there was a wide heterogeneity of federally-financed durations of benefits across U.S. states, ranging from 0 to 47 weeks on top of the regular state-funded benefits with a typical duration of 26 weeks. The available benefit duration in a given state just prior to the reform was endogenous to the economic conditions of the state. Thus the key challenge to a proper inference of the effects of benefits is to ensure that the effects are not confounded by pre-existing differences in employment or labor force trends.

Our formal analysis relies on four distinct empirical strategies to account for the possible trend differences across locations. Common to all of these strategies is the focus on comparing the counties that border each other but belong to different states and are thus subject to different UI policies. This is helpful primarily because underlying trends are likely to be more similar across relatively small neighboring counties than across large states or counties that are far apart. Moreover, the state-level policies are less likely to be endogenous to economic condition of individual border counties.

The first three empirical strategies use the pre- and post-reform data to estimate preexisting trends. The strategies differ in the modeling of trends (they all allow for county level fixed effects and aggregate time effects). The baseline specification, which is the workhorse

in the literature, simply controls for deterministic county level trends. The second model of trends is the latent factor (or interactive effects) model where county-level trends are assumed to be induced by different exposure of each county to various aggregate shocks. This is a very 
flexible model of trends but the estimated aggregate factors and county-specific loadings do not have a clear economic interpretation. Consequently, the third model is a hybrid of the first two where the aggregate factors are represented by aggregate time series which are recognized drivers of the aggregate economy.

The fourth empirical strategy relies on the event study methodology where county-level employment and labor force trends are estimated on the pre-reform data only and the effects of benefits are inferred from the difference in the actual evolution of the labor force and employment following the reform from the prediction based on the pre-reform data.

A simple descriptive analysis shows a much faster employment growth in 2014 in counties that belong to high benefit states relative to their neighboring counties that belong to states with lower benefit durations prior to the reform. It also finds no evidence of mean-reversion at the level of border counties. In other words, in the absence of a change in UI policy, counties that belong to high benefit states in a given quarter are not more likely to grow faster subsequently than the neighboring counties across the state border. Moreover it illustrates that even the least flexible model of county-level trends among those we consider ensures that conditional on the estimated trends, the common trend assumption is satisfied when border counties are compared.

Applying the four formal empirical methodologies, we find that after controlling for heterogeneous county-level employment trends, changes in unemployment benefits have a large and statistically significant effect on employment: a 1 percent drop in benefit duration increases employment by 0.0144 to $0.0233 \log$ point and labor force by 0.0058 to 0.0123 log points. These estimates are based on comparisons of border counties. While this is of direct interest for assessing the effects of local policy changes, it is also desirable to be able to use these estimates to infer the effects of a nation-wide policy change. We documents several empirical facts and provide a simple model that guides the aggregation of these effects. We find that the cut in benefit duration accounted for about 50 to 80 percent of the aggregate employment growth in 2014. Over half of the aggregate employment growth was due the increase in the labor force induced by the policy reform.

While our primary focus in the paper is on total employment and the labor force for which the only data source is the LAUS program of the BLS, we also replicate the entire analysis using the administrative payroll counts from the QCEW. As we discuss above, the 


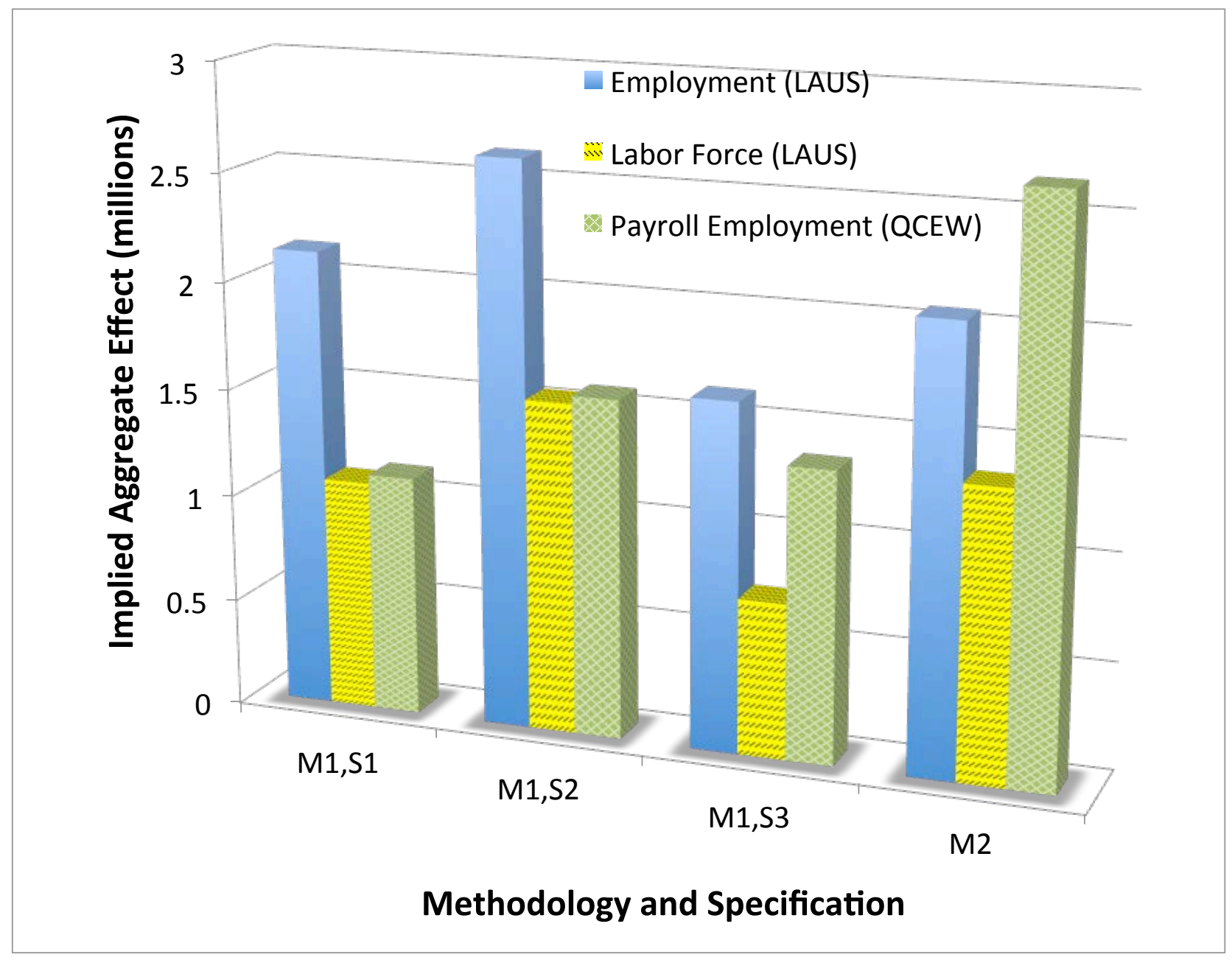

Figure 4: Implied aggregate effects of the benefit cut across methodologies and datasets. M1,S1: Benchmark (Section 4.1); M1,S2: Interactive Effects Model (Section 4.3); M1,S3: "Natural" Factors Model (Section 4.4); M2: Event Study Analysis (Section 6).

two data sets are different in terms of the notion of employment and in terms of coverage. The conclusions they lead to are nevertheless very similar. More generally, all our findings, although based on different methodologies and different data sets, point to the same conclusion that the benefit cut in 2014 lead to significant employment gains and an increase in the labor force. To highlight the similarities between them, Figure 4 collects the estimates of the aggregate employment and labor force growth in 2014 due to the policy reform across all methodologies and data sets we consider.

Our empirical approach is agnostic about the channels which cause employment and labor force participation to increase. Instead of measuring one specific channel, our objective is to measure the aggregate total effect of all potential channels at the same time, including 
equilibrium effects. In particular, our measure also includes the effect of changes in demand on employment and the labor force, while remaining agnostic about the reason for the change in demand. For example, it allows for a drop in demand (e.g. in nontradables) across counties due to the cut in benefit payments as well as an increase in demand as a result of an increase in employment which is due to the benefit cut.

While we did not impose any theoretical restrictions of a particular labor market model on our empirical analysis, the findings are consistent with the predictions of the standard equilibrium labor market search model. For example, the primary labor market effect of a cut in unemployment benefit duration in the framework of Mortensen and Pissarides (1994) is the positive impact on job creation (in such a framework Mitman and Rabinovich (2013) find a quantitatively similar effect of the expiration of benefits on employment in 2014). It is this rise in job creation that leads in equilibrium to the increase in employment. It is also consistent with standard search models that an increase in job availability draws nonparticipants (who are not eligible for benefits either before or after the reform) into the labor market leading to a positive effect on the labor force (for a textbook treatment see Chapter 7 in Pissarides (2000)), even outweighing the potentially countervailing effect of unemployed leaving the labor force after losing eligibility for benefits. Remarkably though, such aggregate labor market implications of unemployment benefit policies have been largely neglected by the empirical literature. The findings in this paper suggest that future research and policy analyses should take these aggregate implications into account. 


\section{References}

BAI, J. (2009): "Panel Data Models with Interactive Fixed Effects," Econometrica, 77, 12291279.

BAI, J. AND S. NG (2002): "Determining the Number of Factors in Approximate Factor Models," Econometrica, 70, 191-221.

Bertrand, M., E. Duflo, and S. Mullainathan (2004): "How Much Should We Trust Differences-In-Differences Estimates?" Quarterly Journal of Economics, 119, 249-275.

Council of Economic Advisers And the Department of Labor (2013): "The Economic Benefits of Extending Unemployment Insurance," Report, The White House.

Dourado, E. And C. Koopman (2015): "Evaluating the Growth of the 1099 Workforce," Mercatus Center, George Mason University.

Gobillon, L. And T. Magnac (2015): "Regional Policy Evaluation: Interactive Fixed Effects and Synthetic Controls," Review of Economics and Statistics, Forthcoming.

Hagedorn, M., J. Handbury, And I. Manovskir (2015): "Demand Stimulus and Inflation: Empirical Evidence," mimeo, University of Pennsylvania.

Hagedorn, M., F. Karahan, I. Manovskit, and K. Mitman (2013): "Unemployment Benefits and Unemployment in the Great Recession: The Role of Macro Effects," NBER Working Papers 19499, National Bureau of Economic Research, Inc.

(2014): "Unemployment Benefits and Unemployment in the Great Recession: The Role of Micro Effects," mimeo, University of Pennsylvania.

Hagedorn, M. And I. Manovskit (2008): "The Cyclical Behavior of Equilibrium Unemployment and Vacancies Revisited," American Economic Review, 98, 1692-1706.

- (2011): "Productivity and the Labor Market: Co-Movement over the Business Cycle," International Economic Review, 52, 603-619.

Holmes, T. J. (1998): "The Effect of State Policies on the Location of Manufacturing: Evidence from State Borders," Journal of Political Economy, 106, 667-705.

Johnston, A. And A. MAs (2015): "Potential Unemployment Insurance Duration and Labor Supply: The Individual and Market-Level Response to a Benefit Cut," Working paper, Princeton University.

Krusell, P., T. Mukoyama, R. Rogerson, and A. Sahin (2015): "Gross Worker Flows over the Business Cycle," Centre for Macroeconomics (CFM) Discussion Paper 1530. 
MacKinlay, A. C. (1997): "Event Studies in Economics and Finance," Journal of Economic Literature, 35, pp. 13-39.

Mitman, K. And S. Rabinovich (2013): "Do Changes in Unemployment Insurance Explain the Emergence of Jobless Recoveries?" mimeo, University of Pennsylvania.

Mortensen, D. T. And C. Pissarides (1994): "Job Creation and Job Destruction in the Theory of Unemployment," Review of Economic Studies, 61, 397-415.

Mulligan, C. B. (2015): "The New Employment and Earnings Taxes Created by Social Programs," Testimony for the U.S. House of Representatives.

Pissarides, C. (1985): "Short-Run Equilibrium Dynamics of Unemployment, Vacancies and Real Wages," American Economic Review, 75, 676-690.

- (2000): Equilibrium Unemployment Theory, Cambridge, MA, second ed.: MIT Press.

Solon, G. (1979): "Labor Supply Effects of Extended Unemployment Benefits," Journal of Human Resources, 14, 247-255. 


\section{Appendices}

\section{Estimating the Number of Factors}

To implement the interactive effects estimator, we need to specify the number of factors. Bai and $\mathrm{Ng}$ (2002) have shown that the number of factors in pure factor models can be consistently estimated based on the information criterion approach. Bai (2009) shows that their argument can be adapted to panel data models with interactive fixed effects. Thus, we define our criterion $C P$ as a function of the number of factors $k$ as:

$$
C P(k)=\hat{\sigma}^{2}(k)+\hat{\sigma}^{2}(\bar{k})\left[k(N+T)-k^{2}\right] \frac{\log (N T)}{N T},
$$

where $\bar{k} \geq r$ is the maximum number of factors, $N$ is the number of pairs, $T$ is the number of time observations, $\hat{\sigma}^{2}(k)$ is the mean squared error, defined as

$$
\hat{\sigma}^{2}(k)=\frac{1}{N T} \sum_{i=1}^{N} \sum_{t=1}^{T}\left(\Delta e_{p, t}-\alpha \mathcal{I}_{t \geq 2013 / Q 4} \Delta b_{p, t}-\lambda_{i}^{\prime}(k) F_{t}(k)\right)^{2}
$$

and $F_{t}(k)$ and $\lambda_{i}^{\prime}(k)$ are the estimated factors and their loadings, respectively, when $k$ factors are estimated. To avoid collinearity, we set $\bar{k}$ to the minimum of seven and $T-1$, one less than the total number of time observations. Our estimator for the number of factors is then given by

$$
\hat{k}=\arg \min _{k \leq \bar{k}} C P(k) .
$$

\section{Aggregation: A Simple Trade Model of the US}

In this section we show that we can use our estimates based on border counties to derive the implications for the induced employment for the aggregate U.S. economy. To this aim, we develop a model where each county is an open economy inside the (closed) US economy. The labor market in each county is governed by a Mortensen Pissarides search and matching model. Each county produces (and consumes) a nontradable and a tradable good. Both sectors, the one producing the tradable good and the one producing the nontradable one, operate in the same labor market and are subject to the same labor market frictions as in s standard Mortensen Pissarides model. The evidence provided in Section 4.2.1 implies that the unemployed do not change where to search for a job in response to changes in benefits. In the model, which we use to study a policy change in benefits, we therefore assume that unemployed search for jobs in their own county only. 
Specifically, each county is described by a discrete time two sector version of the Pissarides (1985, 2000) search and matching model. There is a measure one of infinitely lived workers and a continuum of infinitely lived firms. Workers maximize their expected lifetime utility:

$$
\mathbb{E} \sum_{t=0}^{\infty} \delta^{t} y_{t}
$$

where $y_{t}$ represents income in period $t$ and $\delta \in(0,1)$ is workers' and firms' common discount factor. We denote the sectors producing tradable and non-tradable goods by $\Omega \in\{T, N T\}$. Firms in both the tradable $(\Omega=T)$ and the non-tradable $(\Omega=N T)$ sector have a constant returns to scale production technology that uses labor as the only input (Pissarides (1985, 2000) shows that capital can be added to the model leaving all equations unchanged).

Output of each unit of labor in sector $\Omega$ is denoted by $A^{\Omega}$. There is free entry of firms into both sectors. Firms attract unemployed workers by posting a vacancy at the flow cost $c$. The price of the tradable good is normalized to one $\left(p^{T}=1\right)$ and the price of the non-tradable is denoted $p^{N T}$. Once matched, workers and firms separate exogenously with probability $s$ per period. Employed workers in sector $\Omega$ are paid a wage $w^{\Omega}$, and firms in sector $\Omega$ make accounting profits $p^{\Omega} A^{\Omega}-w^{\Omega}$ per worker each period in which they operate. Unemployed workers get flow utility $z$ from leisure/non-market activity. Unemployed workers can search in either one of the two sectors. In equilibrium they are indifferent in which sector to search. Workers and firms split the surplus from a match according to the generalized Nash bargaining solution. The bargaining power of workers is $\beta \in(0,1)$.

Let $u^{\Omega}$ denote the unemployed searching in sector $\Omega, e^{\Omega}$ the employment in sector $\Omega$ and $v^{\Omega}$ the number of vacancies posted in sector $\Omega$. We refer to $\theta^{\Omega}=v^{\Omega} / u^{\Omega}$ as the market tightness in sector $\Omega$. The number of new matches in each sector is given by a constant returns to scale matching function $m\left(u^{\Omega}, v^{\Omega}\right)$. Employment in each sector evolves according to the following law of motion:

$$
n_{t+1}^{\Omega}=(1-s) n_{t}^{\Omega}+m\left(u_{t}^{\Omega}, v_{t}^{\Omega}\right) .
$$

The probability for an unemployed worker searching in sector $\Omega$ to be matched with a vacancy next period equals $f\left(\theta_{t}^{\Omega}\right)=m\left(u_{t}^{\Omega}, v_{t}^{\Omega}\right) / u_{t}^{\Omega}=m\left(1, \theta_{t}^{\Omega}\right)$. The probability for a vacancy in sector $\Omega$ to be filled next period equals $q\left(\theta_{t}^{\Omega}\right)=m\left(u_{t}^{\Omega}, v_{t}^{\Omega}\right) / v_{t}^{\Omega}=m\left(1 / \theta_{t}^{\Omega}, 1\right)=f\left(\theta_{t}^{\Omega}\right) / \theta_{t}^{\Omega}$. We restrict $m\left(u_{t}^{\Omega}, v_{t}^{\Omega}\right) \leq \min \left(u_{t}^{\Omega}, v_{t}^{\Omega}\right)$.

In each sector $\Omega$, denote the firm's value of a job (a filled vacancy) by $J^{\Omega}$, the firm's value of an unfilled vacancy by $V^{\Omega}$, the worker's value of having a job by $W^{\Omega}$, and the worker's 
value of being unemployed and searching in sector $\Omega$ by $U^{\Omega}$.

$$
\begin{aligned}
J^{\Omega} & =p^{\Omega} A^{\Omega}-w^{\Omega}+\delta(1-s) J^{\Omega^{\prime}} \\
V^{\Omega} & =-c+\delta q\left(\theta^{\Omega}\right) J^{\Omega^{\prime}} \\
U^{\Omega} & =z+\delta\left\{f\left(\theta^{\Omega}\right) W^{\Omega}+\left(1-f\left(\theta^{\Omega}\right)\right) U^{\Omega^{\prime}}\right\} \\
W^{\Omega} & =w^{\Omega}+\delta\left\{(1-s) W^{\Omega^{\prime}}+s U^{\Omega^{\prime}}\right\} .
\end{aligned}
$$

The interpretation is straightforward. Operating firms earn profits $p^{\Omega} A^{\Omega}-w^{\Omega}$ and the matches are exogenously destroyed with probability $s$. A vacancy $\operatorname{costs} c$ and is matched with a worker (becomes productive next period) with probability $q\left(\theta^{\Omega}\right)$. An unemployed worker derives utility $z$ and finds a job next period with probability $f\left(\theta^{\Omega}\right)$. An employed worker earns wage $w^{\Omega}$ but may lose her job with probability $s$ and become unemployed next period.

Nash bargaining with worker bargaining power $\beta$ implies that a worker and a firm split the surplus $S^{\Omega}=J^{\Omega}+W^{\Omega}-U^{\Omega}$ such that

$$
\begin{array}{r}
J^{\Omega}=(1-\beta) S \\
W^{\Omega}-U^{\Omega}=\beta S^{\Omega} .
\end{array}
$$

Free entry implies that the value of posting a vacancy is zero: $V^{\Omega}=0$ and, therefore,

$$
c=\delta q\left(\theta^{\Omega}\right)(1-\beta) S^{\Omega^{\prime}} .
$$

As shown in Hagedorn and Manovskii (2008) the steady state surplus equals

$$
S^{\Omega}=\frac{p^{\Omega} A^{\Omega}-z}{1-\delta(1-s)+\delta f\left(\theta^{\Omega}\right) \beta} .
$$

Plugging this into the free entry condition yields:

$$
\frac{p^{\Omega} A^{\Omega}-z}{1-\delta(1-s)+\delta f\left(\theta^{\Omega}\right) \beta}=\frac{c}{\delta q\left(\theta^{\Omega}\right)(1-\beta)},
$$

and, equivalently,

$$
\frac{1-\delta(1-s)}{\delta q\left(\theta^{\Omega}\right)}+\beta \theta^{\Omega}=\frac{p^{\Omega} A^{\Omega}-z}{c}(1-\beta) .
$$

Since unemployed workers are indifferent between searching in the tradable or in the nontradable sector, $U^{T}=U^{N T}$, which implies that $A^{T}=p^{N T} A^{N T}$ (where we used the normalization $p^{T}=1$ ), $\theta^{T}=\theta^{N T}$ and $w^{T}=w^{N T}$. To see this, suppose $A^{T} \neq p^{N T} A^{N T}$, say 
$A^{T}>p^{N T} A^{N T}$. Then, the above equations imply that $\theta^{T}>\theta^{N T}$ and since wages equal

$$
\begin{aligned}
w^{T} & =\beta A^{T}+(1-\beta) z+c \beta \theta^{T} \\
w^{N T} & =\beta p^{N T} A^{N T}+(1-\beta) z+c \beta \theta^{N T},
\end{aligned}
$$

we also have $w^{T}>w^{N T}$. As a a result, $U^{T}>U^{N T}$, implying by contradiction that $A^{T}=$ $p^{N T} A^{N T}$, which then implies $\theta^{T}=\theta^{N T}$ and $w^{T}=w^{N T}$.

This implies that employment in county $i$ equals $e_{i}=\frac{f\left(\theta_{i}\right)}{s+f\left(\theta_{i}\right)}$, where $\theta_{i}=\theta^{T}=\theta^{N T}$. Employment in the US then equals

$$
E=\sum_{\text {All U.S. counties } i} e_{i} L_{i}
$$

where $L_{i}$ is labor force in county $i$.

In the empirical analysis we compare two neighboring counties $i$ and $j$. The difference in $\log$ employment is $\log \left(e_{i}\right)-\log \left(e_{j}\right)+\log \left(L_{i}\right)-\log \left(L_{j}\right)$, where in this simple model $L_{i}$ and $L_{j}$ are fixed. Our regression then delivers an estimate of the elasticity of employment in county $i$ w.r.t. an increase benefit duration in county $i$, since employment in county $i$ does not depend on the benefit level in other counties. To see this, note that since $\theta_{i}$ solves

$$
\frac{1-\delta(1-s)}{\delta q\left(\theta_{i}\right)}+\beta \theta_{i}=\frac{A^{T, i}-z_{i}}{c}(1-\beta)
$$

it just responds to changes in $z_{i}$ but not to changes in $z_{j}$.

This then implies that this measured elasticity yields also the response of county $i$ employment when we compute the policy induced change in employment for the whole US. Specifically, the percentage employment gain in the US equals

$$
\pi^{E}=\alpha \sum_{\text {All U.S. counties } i}\left(b_{i}^{2014}-b_{i}^{2013}\right) \frac{e_{i}^{2013} L_{i}^{2013}}{E_{U S}^{2013}}
$$

where $\alpha$ is the estimated elasticity at the county level and $b$ is the logarithm of benefit duration.

The corresponding gain in the total number of employed then equals

$$
\Delta^{E}=\frac{\pi^{E} \times E_{U S}^{2014}}{1+\pi^{E}} .
$$

The same derivations for employment can be applied to the labor force as well. Indeed, Pissarides (2000) shows in a more complex model, where heterogenous households take a participation decision, that the labor force can be written as a function of market tightness as well. The same derivations as above in the more elaborated model imply that labor force 
in a county depends on market tightness in that county only (and not on market tightness in other counties). Our regression then delivers again an estimate of the elasticity of the labor force in county $i$ w.r.t. an increase benefit duration in county $i$ (since labor force in county $i$ does not depend on the benefit level in other counties). And we can again use this estimate at the county level to compute the percentage change of the aggregate labor force and the gain in the the total number of labor force participants. 


\section{Appendix Figures}

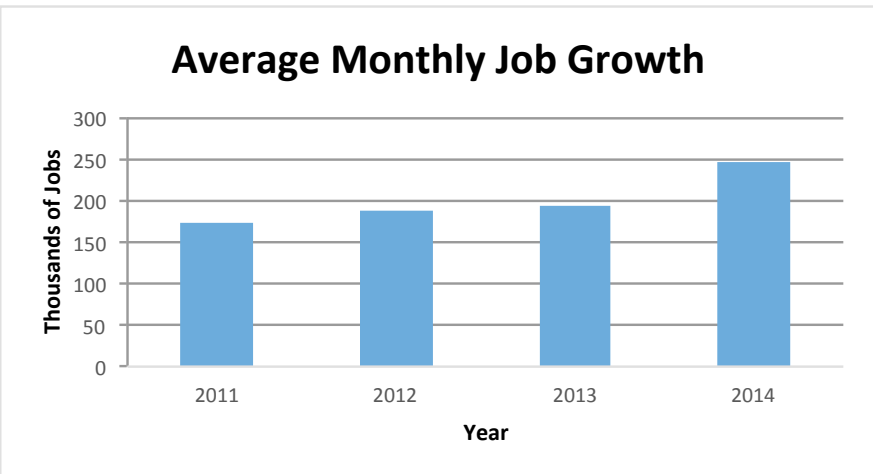

(a) Monthly Job Growth.

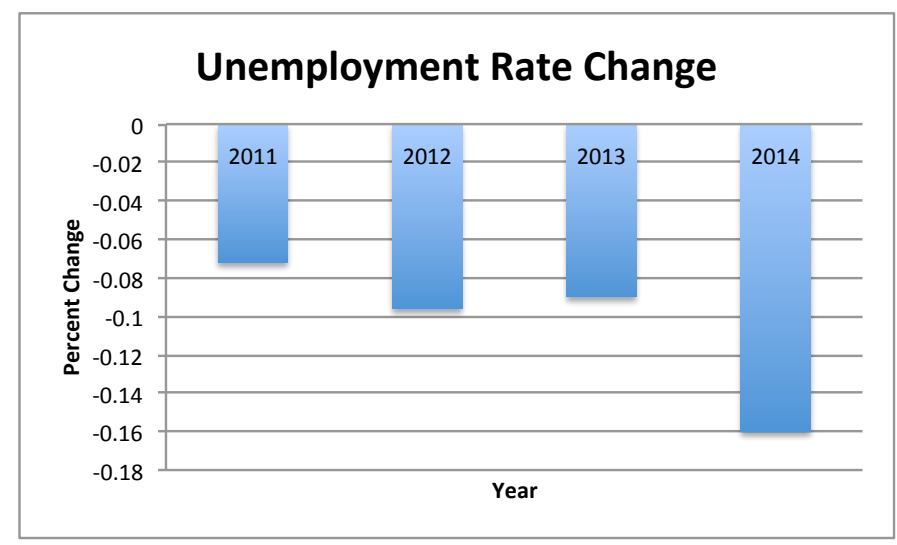

(c) Unemployment Rate Change.

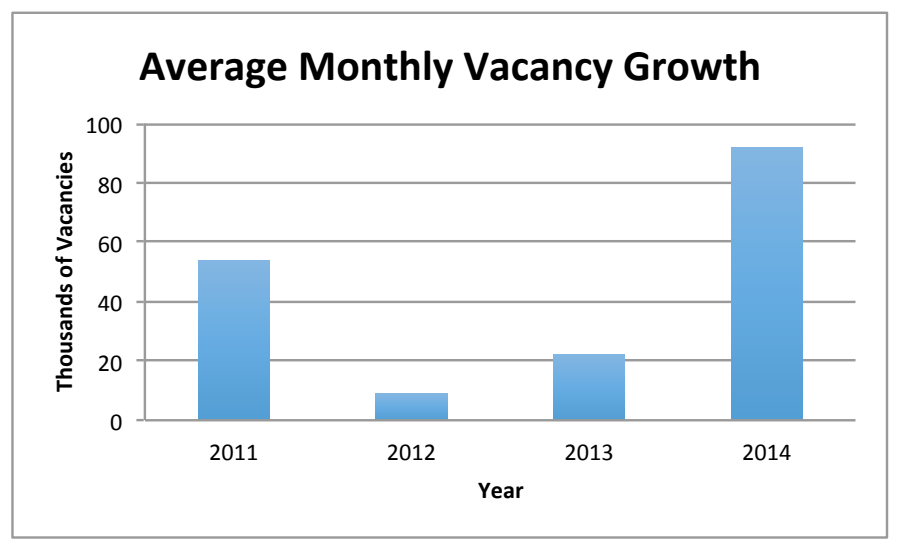

(e) Monthly Vacancy Growth.

\section{Employment Population Ratio}

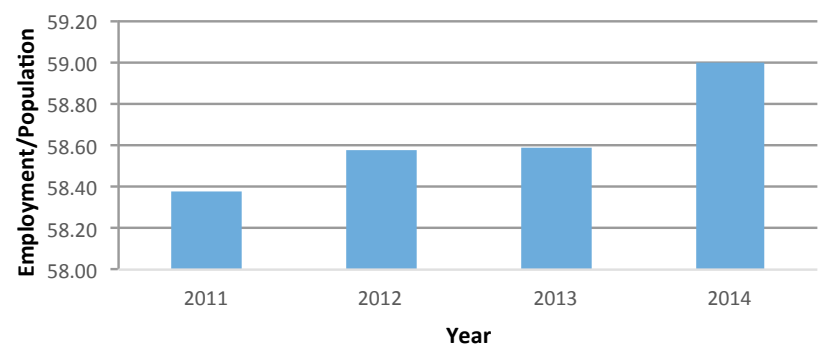

(b) Employment to Population Ratio.

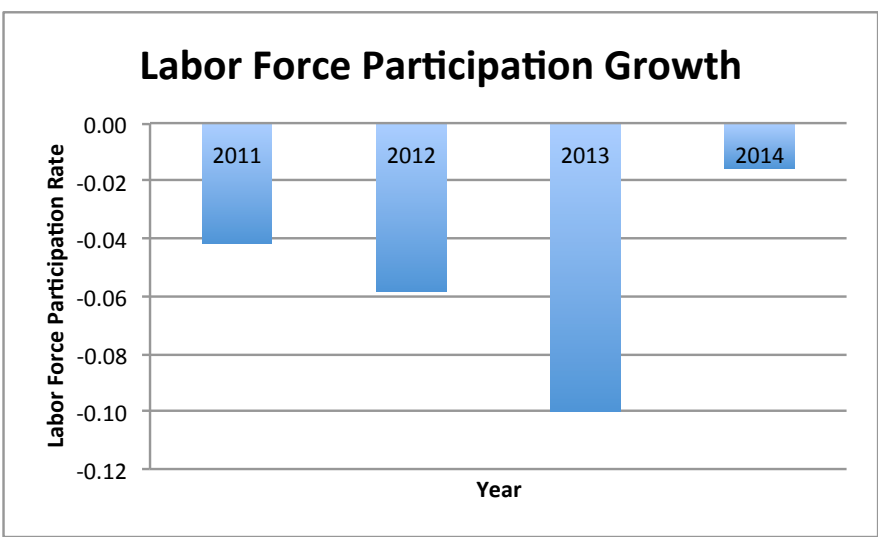

(d) Labor Force Participation Growth.

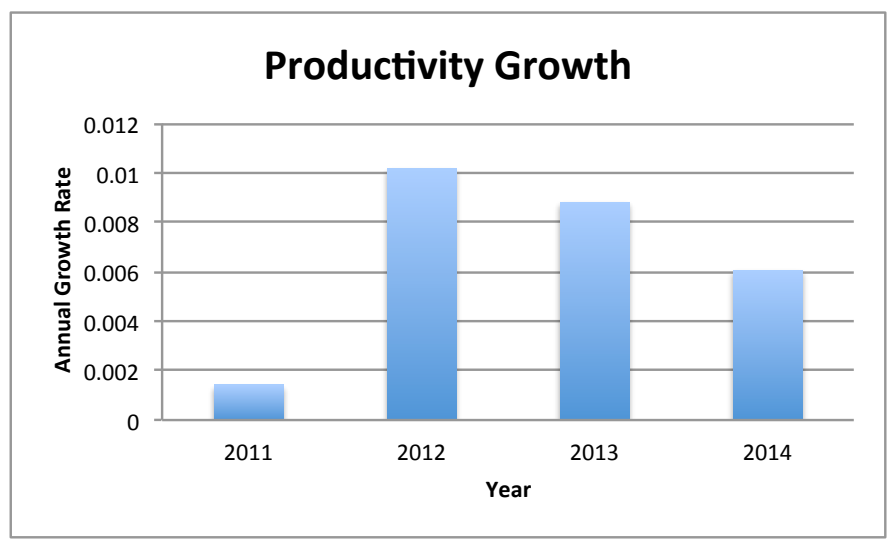

(f) Productivity Growth.

Figure A-1: U.S. Labor Market Performance in 2014.

Note - Data series downloaded from the Bureau of Labor Statistics website http://www.bls.gov/data/ on 01/09/2015 with the following series identifiers:

Panel (a) - CES0000000001, Panel (b) - LNS12300000, Panel (c) - LNS14000000,

Panel (d) - LNS11300000, Panel (e) - JTS00000000JOL, Panel (f) - PRS85006093. 